\title{
Identification of Determinants of the Speed-Reducing Effect of Pedestrian Refuges in Villages Located on a Chosen Regional Road
}

\author{
Alicja Sołowczuk and Dominik Kacprzak * \\ Department of road and bridge engineering, West Pomeranian University of Technology Szczecin, \\ 71-311 Szczecin, Poland; alicja.solowczuk@zut.edu.pl \\ * Correspondence: kdim.zut@gmail.com or dominik.kacprzak@zut.edu.pl; Tel.: +48-(091)-449-40-36
}

Received: 3 April 2019; Accepted: 19 April 2019; Published: 25 April 2019

check for updates

\begin{abstract}
Traffic calming, as a traffic engineering discipline, is becoming an increasingly important aspect of the road engineering process. One of the traffic calming treatments are pedestrian refuges-raised islands located on or at the road centreline. This paper presents factors relevant to the performance of this kind of traffic calming devices retrofitted on the stretches of regional roads in village areas. To this end, speed surveys were carried out before and after the islands in each direction on purposefully chosen test sections. In order to identify the determinants, each test section was characterised by features including the symmetry of the road layout geometry, surrounding features and the existing traffic signs and, last but not least, visibility of the road ahead. The survey data were used by the authors to perform analyses in order to group the speeds at the pedestrian refuges and relate them to specific factors and, finally, identify the determinants of speed reduction. In this way, the authors arrived at a conclusion that the performance of pedestrian refuges depends on a number of factors rather than solely on their geometric parameters. The analyses showed that the pedestrian refuge geometric parameters, features located in its proximity that influence the driver's perception and placement of appropriate marking, can, in combination, result in achieving the desired speed reduction and ensure safety of non-motorised users. These hypotheses were tested on a stretch of a regional road in village area at three points of the process: before upgrading, after installation of pedestrian refuges, and after retrofitting of enhancements.
\end{abstract}

Keywords: pedestrian refuge; speed reduction; visibility; surrounding environment

\section{Introduction}

Economic growth increases the road traffic and the associated problems are bound to intensify as a result. In the case of villages located on primary routes (further called regional roads) this growth of traffic is more conspicuous, as compared to small or bigger towns, due to accumulation of problems on a relatively short stretch of the road. A shortage of road by-passes in Poland results in the road routes cutting through the centres of settlements, this affecting the quality of life of the local community.

The main factor which, in most cases, has a direct bearing on both the number of road incidents and their severity is the speed of vehicular traffic. Hence, one of the key issues is ensuring safety on the pedestrian crossings in villages. To this end, various traffic calming treatments are installed, positioned both in the entry zones and in the village centre areas. The latter include pedestrian refuges whose primary function is to protect vulnerable road users (VRU). According to the guidelines of [1] the pedestrian refuges should be provided where it is desired to obtain reduction of the 85th percentile speed $v_{85}$ to below $50 \mathrm{~km} / \mathrm{h}$.

Incorporation of pedestrian refuges in the design of roads is a most important issue from the traffic safety improvement viewpoint. According to the most recent studies [2] over $30 \%$ of accidents 
involving pedestrians occur on the pedestrian crossings and excessive speed is identified as their cause. The probability of fatality increases with the impact speed, i.e., the speed at which the vehicle hits the pedestrian. Based on the review of the most recent research publications it has been concluded that the pedestrian crossing type has a bearing on the speeds at which it is passed by vehicles, as demonstrated by the speed survey data. The distance from which the driver spots the pedestrian is also most relevant to the theoretical impact speed [3]. Visibility studies confirmed that pedestrian refuges, due to their central location, make the drivers focus their vision on this obstacle, i.e., on the central area of the road. Looking from a distance, the driver can sooner identify the pedestrian crossing and spot a pedestrian about to cross the street. Facing the island ahead, the drivers become more focussed and alert and this increases the distance from which they can spot a pedestrian and reduces the risk of accidents. Moreover, pedestrian refuges create a perceived reduction of the carriageway width, increasing the amount of speed reduction, as compared to conventional pedestrian crossings [4]. Therefore, pedestrian refuges are ranked as one of the best measures to improve traffic safety on pedestrian crossings.

According to the U.S. traffic survey data published in [1], for the road under analysis speed reduction in the range of $13-23 \%$ can be expected on the road under analysis after it has been provided with pedestrian refuges. The purpose of this research was to verify if the actual speed reductions achieved in Poland correspond to the U.S. survey results published in [1]. To this end, a number of free-flow and stable-flow speed surveys were carried out in a few villages located on regional roads with pedestrian refuges positioned in the entry zones and in the village centre areas. The upgrading project was carried out in the period 2012-2016 and to date, only isolated road incidents occurred from completion of the works. Only in one village a few incidents were noted in that period, yet none of them involved pedestrians. As such, the scope of this research has been limited to the vehicular speed issue. By selecting recently upgraded stretches of regional roads the authors excluded the effect of deteriorated pavements, lack of footways and other factors that could influence the speeds of travel. This paper presents the results of analyses performed on the survey data.

\section{Review of Engineering Requirements Given in Various Design Manuals}

The basic engineering requirements to be applied for pedestrian refuges located in Poland are given in $[1,5]$. The key points concern maintaining the width of the travel lane alongside the pedestrian refuge, as given in the Design Guidelines [6] depending on the level of service of the road and use of symmetric 1:5 to 1:10 tapered hatched markings as the approach end treatments. However, the guidelines [7] are not specific if the lines of $\mathrm{P}-7 \mathrm{~b}$ pavement marking should be extended up to the island nose or to the meeting point with the P10 or P11 line marking, (for the meaning and pictures of signs referred to by their acronyms see the table in the Appendix A). However, they give a recommendation the travel lane width should be measured between the centres of the marking lines or between the line centre and face of the curb. Furthermore, guidelines [5] recommend using different taper geometries depending on the pedestrian island position (in the entry zone, central area or in the vicinity of public buildings respectively), with more aggressive design for the village central areas and less aggressive for the entry zones.

The Swedish guidelines [8] in turn do not give detailed geometric parameters for pedestrian refuges. They, however, recommend two different treatments to accompany the pedestrian refuges in lightly trafficked (yet including heavy goods vehicles) and heavily trafficked roads respectively. These are: raising of pavement-to facilitate crossing the road by pedestrians in the first case and installation of post-and-chain barriers as a measure to prevent illegal crossing in the latter case.

In the U.S. guidelines [9] the recommendations concern primarily the island width, which should be in the range of 1.2 to $1.8 \mathrm{~m}$ and the lengths of P-21 and P-7b line markings, which should be $30.48 \mathrm{~m}$ $(100 \mathrm{ft})$ in built-up areas and $60.96 \mathrm{~m}(200 \mathrm{ft})$ in rural areas. Symmetricity of both the island and the hatched markings is required therein. Moreover, $\mathrm{P}-4$ solid line pavement marking is recommended to be placed before the hatched marking over the same length as the taper length. Raised pedestrian crossings 
are recommended for less busy roads and refuges flush with the road surface are recommended in the case of narrower islands. In guidelines [9] much emphasis is put on installation of raised kerbing and conspicuous markers which is primarily associated with the motorist's perception of closer and more distant parts of the route and outlines of the nearby houses. Visual perception of the road signs and pavement markings by the motorist is covered, for example, in [10]. The issues pertaining to perception of 2D and 3D symmetric images and the effect of this perception on taking decisions by the motorist are covered in [11,12].

Also, the German guidelines [13] pay special attention to the motorist's perception, with the focus put on the visibility of pedestrians to motorists approaching the pedestrian refuge and the need of artificial lighting installed at a height of 3.5-4.5 $\mathrm{m}$ to improve visibility when required. The island widths given in the German guidelines [13] are much greater than the values of the U.S. guidelines [9]. A minimum width of $2.0 \mathrm{~m}$ is recommended, increased to $2.5-3.0 \mathrm{~m}$ if the crossing is intended to be used by cyclists and wheelchair users. The width of travel lanes recommended in [13] to ensure smooth traffic flow is 3.25-3.75 m, depending on the traffic composition. With a greater percentage of heavy vehicles, the lanes should be $3.5 \mathrm{~m}$ or $3.75 \mathrm{~m}$ wide. With the heavy vehicles, percentage of $1-3 \%$ the travel lanes can be $3.25 \mathrm{~m}$ wide. In places where an increased number of over-dimensional vehicles involved in seasonal agricultural activities is expected, the geometry of islands should be adjusted accordingly by providing $1.0 \mathrm{~m}$ wide overrun strips at the outer carriageway edge, made of irregular cobblestones or fieldstone/flagstone pavers.

In guidelines [13] a lot of attention is paid to the location of pedestrian crossings on the central islands of various shapes installed as traffic calming measures in the entry zones of settlements. In order to warn the motorists of the change of carriageway geometry and enhance understanding the route and layout of the carriageway, the German guidelines recommend highlighting the chicanes by planting of trees or placing street furniture items. The issue of motorist's perception and comprehension of road signs is extensively covered in literature [10-12].

According to the design guidelines of [10], for safety reasons, the central islands used as the village entry treatment should not be combined with pedestrian crossings. This said, local conditions may sometimes require combining these two elements at the village gateway. In these cases, the crossing should be placed on the so-called safe side, i.e., where the drivers are expected to have reduced their speed, and enhanced by trees or street furniture elements.

\section{Parameters of the Test Sections}

For testing the effect of pedestrian refuges on vehicular speed in their vicinity a few villages were chosen where different refuge islands had been installed: conventional, symmetric about the carriageway centreline and deflecting the path of travel by $1 \mathrm{~m}$ on each side (Figure 1a-c), one non-conventional $2.5 \mathrm{~m}$ wide pedestrian refuge island on one side of the centreline (Figure 1d) and one asymmetric pedestrian refuge incorporating a $4 \mathrm{~m}$ wide island imposing asymmetric lateral shifts by $1 \mathrm{~m}$ and $3 \mathrm{~m}$ respectively (Figure 1e). One case under analysis was a $2 \mathrm{~m}$ wide pedestrian refuge located in the entry zone in place of centre island (Figure 1a).

Most of the analysed $2 \mathrm{~m}$ wide pedestrian refuges were accompanied with a 1:5 tapered marking except for one case with the 1:6.5 rate at village centre side and 1:8 rate at the entry zone side (Figure 1c). In another case, a $4 \mathrm{~m}$ wide asymmetric pedestrian refuge had 1:15 tapered marking at the side imposing lateral shift by $1 \mathrm{~m}$ (Figure 1e). In addition to asymmetric positioning another unusual feature of this pedestrian refuge was an open bus bay positioned tangentially to the travel lane after the island which the drivers took benefit of by accelerating right after passing the pedestrian crossing rather than slowing down below to the upstream speed. 


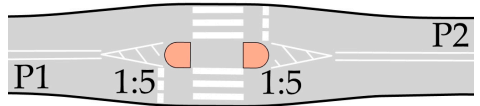

(a)

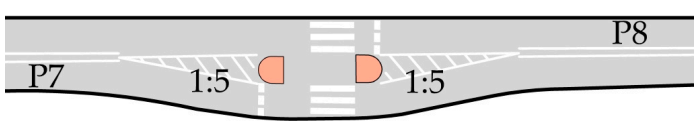

(d)

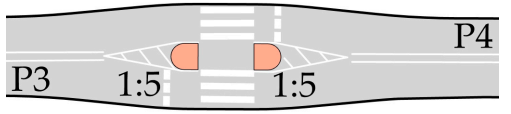

(b)

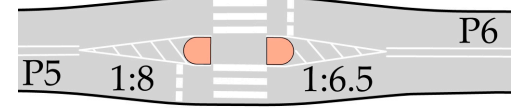

(c)

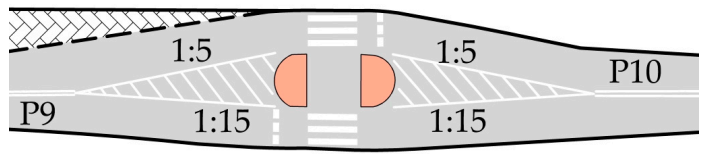

(e)

Figure 1. Diagrams of the analysed pedestrian refuges: (a) symmetric, $2 \mathrm{~m}$ wide (entry zone); (b) symmetric, $2 \mathrm{~m}$ wide (entry zone; after centre island); (c) symmetric, $2 \mathrm{~m}$ wide (between two centre islands, both positioned on one side of the centreline); (d) $2.5 \mathrm{~m}$ wide pedestrian refuge on one side of the centreline (end of entry zone/beginning of the village centre area); (e) asymmetric, $4 \mathrm{~m}$ wide (village centre, asymmetric shift of the lane alignments by $1 \mathrm{~m}$ and $3 \mathrm{~m}$ respectively). The test sections P1, P2, $\ldots \mathrm{P} n$, are marked on the respective travel lanes before the pedestrian refuges, in this way indicating the traffic direction under analysis.

All of the above-mentioned pedestrian refuges were located in a built-up area marked with D-42 entry signs. The B-33 speed limit sign was not placed in the immediate vicinity of the pedestrian refuge in any of the analysed cases. The daytime speed limit in residential areas in Poland is $50 \mathrm{~km} / \mathrm{h}$. The pedestrian refuges chosen for the research feature various geometric parameters, different visibility of the road ahead and traffic control schemes. One of them has a conventional shape, includes a $2 \mathrm{~m}$ wide island and approach end treatment with P-21 1:5 tapered markings (Figure 2).

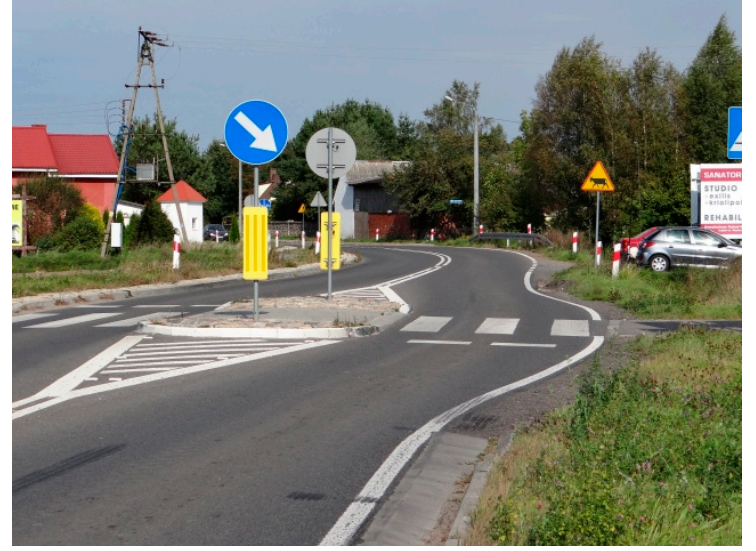

(a)

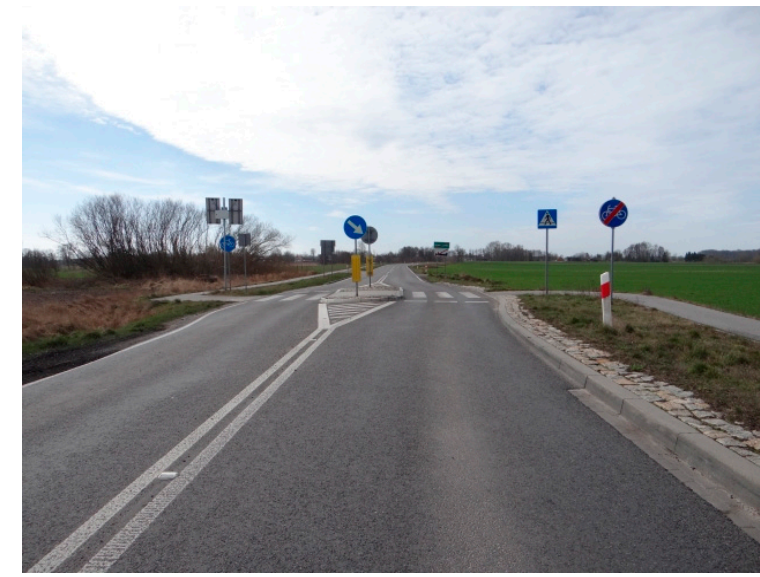

(b)

Figure 2. Test sections $\mathrm{P} 1$ and P2 with the pedestrian refuge positioned between the end of entry zone and beginning of the village centre area: (a) P1—entry zone; (b) P2—exit zone.

Two other pedestrian refuges under analysis were located on the stretches surrounded by residential buildings in close proximity (Figure 3) or without any buildings in the surrounding environment (Figure 4). With most of analysed central refuges situated in the settlement areas (Figures 1-10), in two cases they were located in the entry zones, preceded by gateway islands (Figures $3 \mathrm{~b}$ and $4 \mathrm{a}$ ). These pedestrian refuges were located quite close to the gateway islands, namely ca. $170 \mathrm{~m}$ away. In one case, a very good view was ensured in both directions of travel (Figure 3). The pedestrian refuge included a $2 \mathrm{~m}$ wide island and 1:5 tapered markings. In the other case, the gateway island positioned on the approach lane was followed by a horizontal curve (Figure 4b) completely obscuring view on the course of the departure section. The pedestrian refuge presented in Figure 4 has a $2 \mathrm{~m}$ wide island and hatched markings with different taper rates of 1:8 on the entry side (Figure 4a) and 
1:6.5 on the departure side (Figure $4 \mathrm{~b}$ ), viewing in the direction of the village centre, to accommodate the nearby collector road junction.

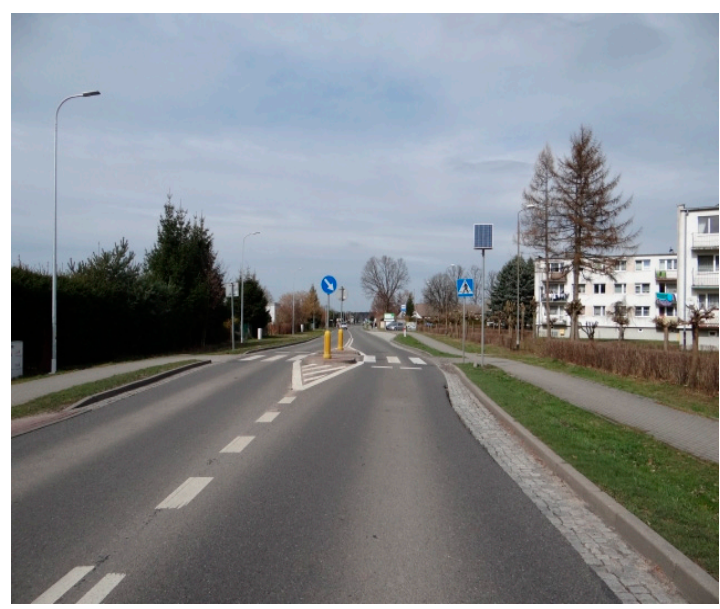

(a)

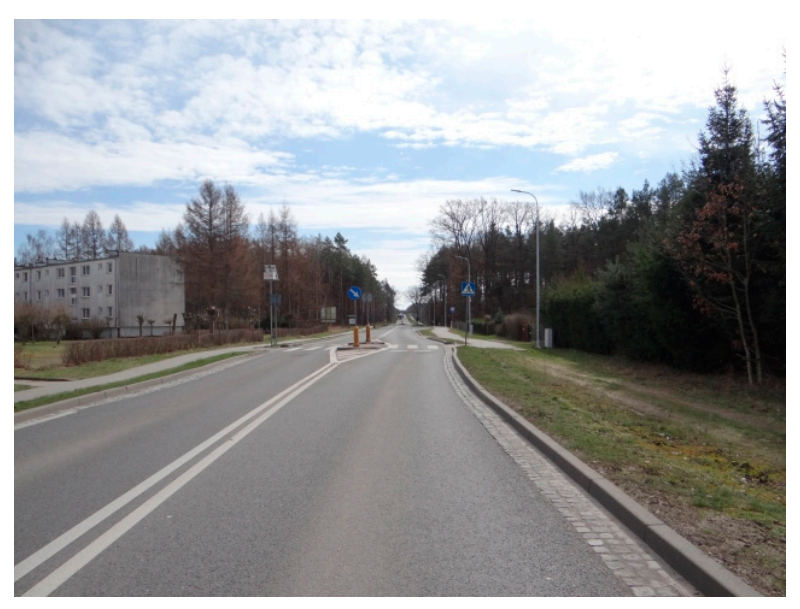

(b)

Figure 3. Test sections $\mathrm{P} 3$ and $\mathrm{P} 4$, pedestrian refuge placed $170 \mathrm{~m}$ after the gateway island symmetrical about the road centreline: (a) P3 — exit zone; (b) P4—entry zone.

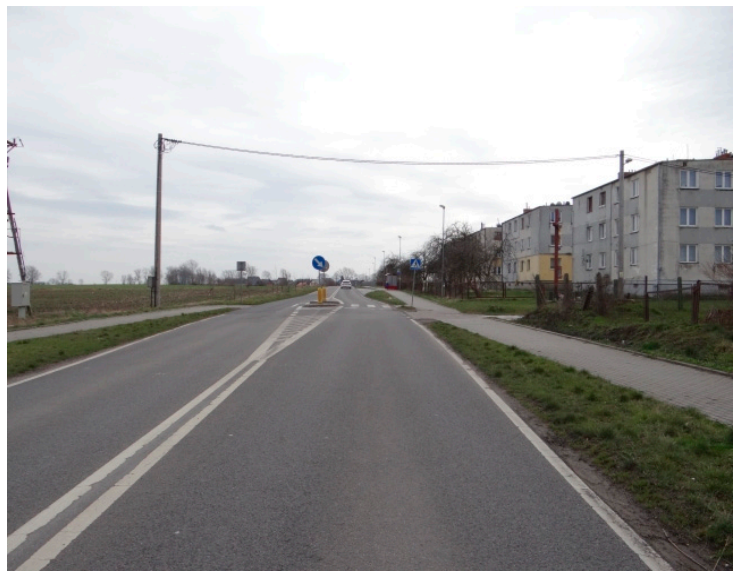

(a)

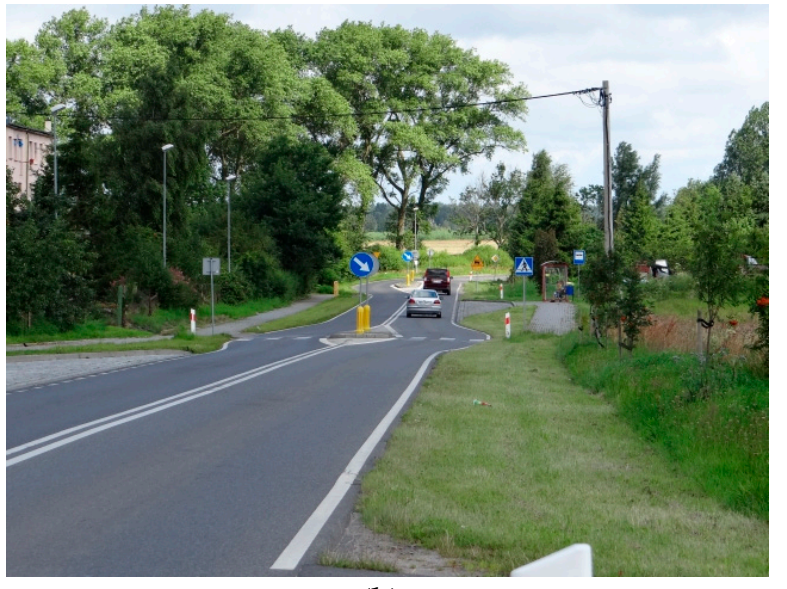

(b)

Figure 4. Test sections P5 and P6, pedestrian refuge placed $170 \mathrm{~m}$ after gateway island positioned on one side of the road centreline: (a) P5—entry zone; (b) P6 —exit zone.

One of the analysed refuges was located on one side of the centreline and included a $2.5 \mathrm{~m}$ wide island (Figure 5). It was situated between the end of the entry zone and the beginning of the village centre area with nearby buildings spaced $80 \mathrm{~m}$ away from the roadway edge. Hatched, 1:5 tapered markings were applied. The buildings were preceded by a bridge lined with a high curb and parapets being visible side obstacles. The bridge was followed by a curve to the right, that reduced the view of the further course of the road (Figure 5a). Viewing in the departure direction, the bridge approach lane was close to the buildings in the village centre area and after the pedestrian refuge the road was surrounded by a forest without any buildings (Figure $5 b$ ). 


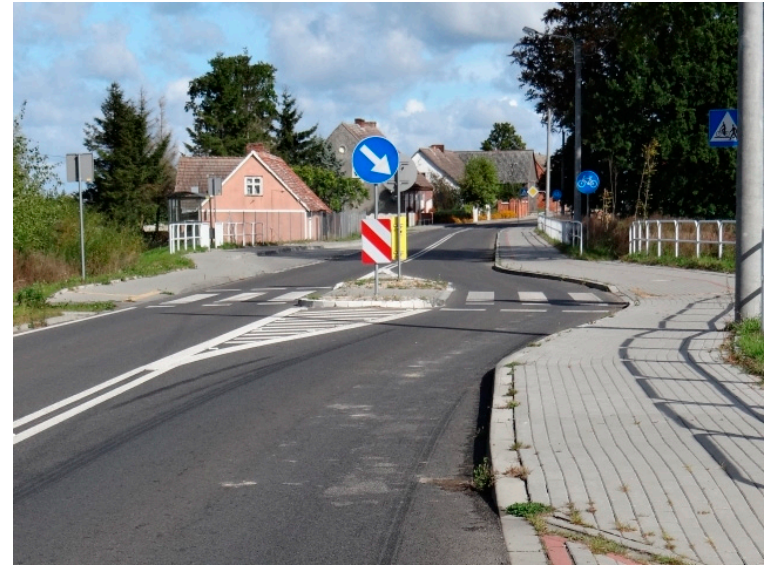

(a)

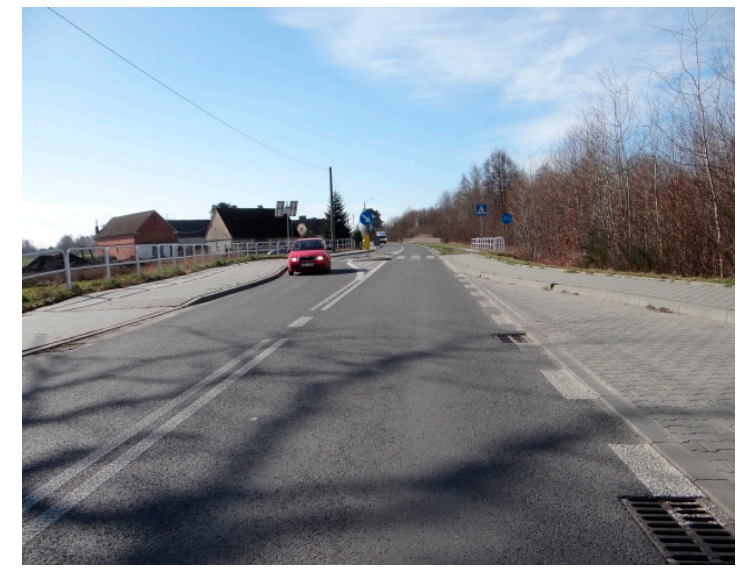

(b)

Figure 5. Test sections P7 and P8 between the end of entry zone and beginning of the village centre area: (a) P7-pedestrian refuge on one side of the centreline imposing large lateral shift by $2.5 \mathrm{~m}$; (b) P8-departure lane without any imposed lateral shift.

The last case was an unusual, asymmetric pedestrian refuge situated in the village centre area between two bus bays (Figure 6). It included a $4 \mathrm{~m}$ wide asymmetric island. In the direction towards the bus bay the travel path is deflected by $1 \mathrm{~m}$ and there is a 1:15 tapered marking (Figure 6a). With the nearby positioned open bus bay, the island was designed to impose a $3 \mathrm{~m}$ lateral shift and a 1:5 tapered marking was used (Figure 6b). This arrangement resulted in a very sharp lateral deflection of traffic on the approach to the pedestrian refuge and a very convenient departure alignment with possible entering the open bus bay. Very good vision on the road ahead was ensured in both directions of travel.

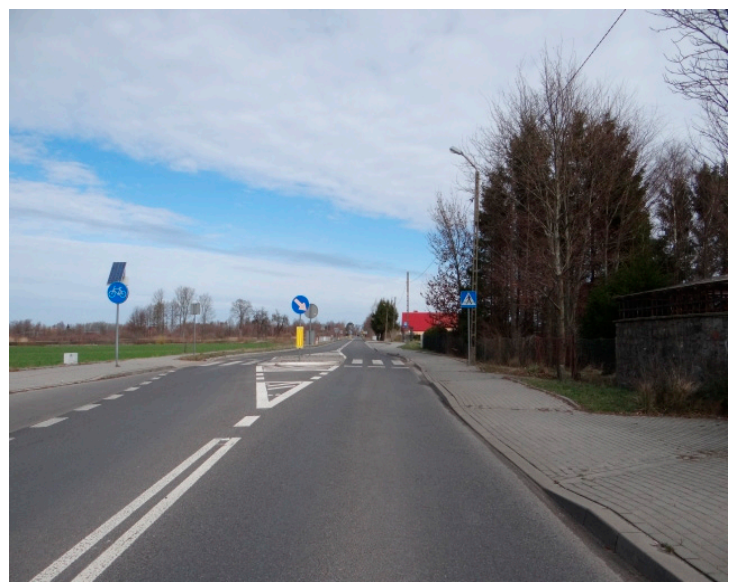

(a)

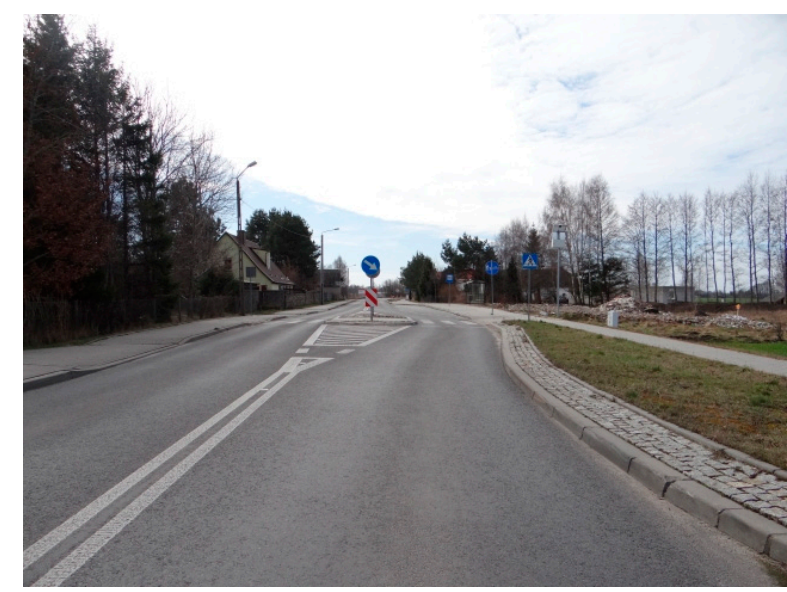

(b)

Figure 6. Test sections P9 and P10 in the village centre area: (a) P9—small lateral shift (1 m); (b) P10—big lateral shift $(3 \mathrm{~m})$.

Table 1 compiles the surrounding environment and land characteristics and visibility conditions on the test sections before the pedestrian refuges and after the pedestrian refuges under analysis. 
Table 1. Characteristics of the test sections.

\begin{tabular}{cccccc}
\hline \multirow{2}{*}{ No. } & \multicolumn{2}{c}{ Conditions before Refuge Island } & \multicolumn{2}{c}{ Conditions after Refuge Island } & \multirow{2}{*}{ Visibility Conditions ${ }^{\mathbf{1}}$} \\
\cline { 2 - 5 } & Surroundings & Buildings & Surroundings & Buildings & \\
\cline { 1 - 4 } P1 & rural area & lack of buildings & forest & lack of buildings & nearby buildings in view \\
P2 & residential area & distant buildings & rural area & lack of buildings & good visibility \\
P3 & forest & lack of buildings & residential area & distant buildings & good visibility \\
P4 & residential area & lack of buildings & forest & lack of buildings & good visibility \\
P5 & residential area & distant buildings & rural area & lack of buildings & good visibility \\
P6 & rural area & lack of buildings & rural area & lack of buildings & 240 m sight distance \\
P7 & forest & lack of buildings & residential area & nearby buildings & 170 m sight distance \\
P8 & residential area & nearby buildings & forest & lack of buildings & good visibility \\
P9 & residential area & nearby buildings & residential area & nearby buildings & buildings \& bus bay in view \\
P10 & residential area & nearby buildings & residential area & lack of buildings & good visibility \\
\hline \multicolumn{7}{c}{ 1 Visibility of the road ahead are given in relation to the pedestrian refuge axis. }
\end{tabular}

Wherever "before" appears in this article it designates a location (or locations) upstream of the island viewing in the direction of traffic.

Wherever "after" appears in this article it designates a location (or locations) downstream of the island viewing in the direction of traffic.

\section{Study Method}

For all the test sections the speed readings were taken between 10:00-15:00 hrs. during weekday, including ca. 70 veh. in free-flow and up to 100 veh. in stable-flow (more congested) conditions. The equipment used both before and after the pedestrian refuges were synchronised SR4 traffic detection devices equipped with automatic speed data logging function (SR4-brand name of the devices used in the survey - Speed Displays Traffic Detection). Additionally, hourly traffic volumes were measured in each case, including determination of the percentages of heavy goods vehicles. The speed data were grouped by direction to calculate the 85 th percentile speed $v_{85}$, average free-flow speed $v_{a v}$ and stable-flow speed $v_{a v} p p$ and also the before/after speed difference $\Delta v$ and, finally, the speed variation ratio $u_{p}=\Delta v^{\text {before-after }} / v^{\text {before }}$ in $\%$. The calculation results are presented in Table 2 .

Table 2. Speed distribution parameters, upstream/downstream (before/after) speed difference and speed variation ratio.

\begin{tabular}{|c|c|c|c|c|c|c|c|c|c|c|c|c|}
\hline \multirow[t]{2}{*}{ No. } & \multicolumn{3}{|c|}{$\begin{array}{c}\text { Speed before Refuge } \\
v^{\text {before }}, \mathrm{km} / \mathrm{h}\end{array}$} & \multicolumn{3}{|c|}{$\begin{array}{c}\text { Speed after Refuge } \\
v^{\text {after }}, \mathrm{km} / \mathrm{h}\end{array}$} & \multicolumn{3}{|c|}{$\begin{array}{c}\text { Speed Difference } \\
\Delta v, \mathrm{~km} / \mathrm{h}\end{array}$} & \multicolumn{3}{|c|}{$\begin{array}{c}\text { Speed Variation Ratio } \\
u_{p}, \%^{1}\end{array}$} \\
\hline & $v_{85}$ & $v_{a v}$ & $v_{a v} p p$ & $v_{85}$ & $v_{a v}$ & $v_{a v} p p$ & $v_{85}$ & $v_{a v}$ & $v_{a v} p p$ & $v_{85}$ & $v_{a v}$ & $v_{a v} p p$ \\
\hline $\mathrm{P} 1$ & 76.5 & 65.4 & 63.8 & 65.5 & 58.4 & 56.8 & 11.0 & 7.0 & 7.0 & 14 & 11 & 11 \\
\hline P2 & 58.0 & 51.2 & 50.8 & 63.9 & 56.8 & 56.8 & -5.9 & -5.6 & -6.1 & -10 & -11 & -12 \\
\hline P3 & 64.0 & 55.8 & 53.9 & 66.7 & 56.8 & 54.7 & -2.7 & -1.0 & -0.9 & -4 & -2 & -2 \\
\hline P4 & 58.7 & 51.9 & 50.7 & 63.5 & 54.1 & 51.3 & -4.8 & -2.2 & -0.6 & -8 & -4 & -1 \\
\hline P5 & 64.3 & 55.5 & 55.5 & 71.1 & 60.8 & 60.8 & -6.8 & -5.4 & -5.4 & -10 & -10 & -10 \\
\hline P6 & 71.0 & 62.7 & 62.7 & 63.6 & 58.0 & 58.0 & 7.4 & 4.7 & 4.7 & 10 & 7 & 7 \\
\hline P7 & 75.9 & 67.6 & 67.4 & 53.4 & 48.1 & 47.2 & 22.5 & 19.5 & 20.3 & 30 & 29 & 30 \\
\hline P8 & 53.2 & 47.8 & 47.5 & 68.0 & 59.2 & 58.4 & -14.8 & -11.4 & -10.9 & -28 & -24 & -23 \\
\hline P9 & 56.9 & 52.4 & 51.7 & 54.2 & 47.6 & 47.1 & 2.7 & 4.8 & 4.6 & 5 & 9 & 9 \\
\hline P10 & 56.1 & 44.9 & 44.3 & 62.9 & 53.8 & 53.5 & -6.8 & -8.9 & -9.2 & -12 & -20 & -21 \\
\hline
\end{tabular}

${ }^{1}$ Speed variation ratio is often used in traffic calming studies, calculated as follows: $u_{p}=\Delta v^{\text {before-after }} / v^{\text {before }}$ and given in $\%$.

The measurement data were subjected to statistical inference. After conventional parametric tests, normality of distribution of the respective data sets was assessed with Kolmogorov-Smirnov test and the ranges of results were confirmed with homogeneity tests to remove outliers. The Kolmogorov-Smirnov (K-S) test, $\chi^{2}$ independence test and, $\chi^{2}$ median test were carried out for the whole data set comprising the upstream and downstream speeds to check if they belong to one or two different populations. The results of the statistical tests performed on the upstream and downstream speeds are presented in Table 3. 
Table 3. Results of statistical tests.

\begin{tabular}{|c|c|c|c|c|c|c|}
\hline \multirow[t]{2}{*}{ Test Section } & \multicolumn{2}{|c|}{$\begin{array}{c}\text { Kolmogorov-Smirnov Test } \lambda^{1} \\
H_{0}: F_{1}\left(v^{\text {before }}\right)=F_{2}\left(v^{\text {after }}\right) \\
H_{1}: F_{1}\left(v^{\text {before }}\right) \neq F_{2}\left(v^{\text {after }}\right)\end{array}$} & \multicolumn{2}{|c|}{$\chi^{2}$ Independence Test ${ }^{2}$} & \multicolumn{2}{|c|}{$\chi^{2}$ Median Test ${ }^{3}$} \\
\hline & Free Flow & Stable Flow & Free Flow & Stable Flow & Free Flow & Stable Flow \\
\hline P1 & 2.20 & 2.28 & 2.61 & 4.26 & 7.03 & 13.46 \\
\hline P2 & 1.65 & 1.73 & 12.40 & 13.16 & 8.36 & 3.67 \\
\hline P3 & 0.70 & 0.73 & 0.83 & 0.09 & 8.45 & 0.59 \\
\hline P4 & 0.55 & 0.33 & 0.16 & 0.45 & 10.08 & 0.67 \\
\hline P5 & 1.03 & 1.03 & 0.55 & 5.28 & 12.13 & 12.13 \\
\hline P6 & 1.35 & 1.35 & 2.30 & 5.79 & 6.40 & 6.40 \\
\hline P7 & 4.56 & 5.22 & 60.42 & 85.01 & 77.20 & 103.91 \\
\hline P8 & 3.07 & 3.14 & 38.47 & 40.02 & 35.51 & 36.21 \\
\hline P9 & $4 ., 08$ & 4.51 & 18.68 & 32.48 & 52.05 & 61.38 \\
\hline P10 & 1.13 & 1.61 & 0.02 & 16.60 & 4.33 & 1.60 \\
\hline $\begin{array}{l}{ }^{1} \text { For the adopt } \\
P\left\{V^{\text {before }}=v^{\text {befor }}\right. \\
v^{\text {before }}{ }_{i} \text { and } v^{\text {after }} \\
\text { table the critic }\end{array}$ & $\begin{array}{l}\text { significance } 1 \\
P\left\{V^{\text {after }}=v^{a f t}\right. \\
\text { re the respec }\end{array}$ & $\begin{array}{l}\text { of } \alpha=0.05 \text { th } \\
H_{1}: P\left\{V^{\text {before }}=\right. \\
\text { peed values }\end{array}$ & $\begin{array}{l}\text { cal value } \\
\text { re } i, V^{\text {after }} \\
\text { with the }\end{array}$ & $\begin{array}{l}=1.36 .{ }^{2} \mathrm{H}_{0} \\
\left.{ }_{i}\right\} \neq P\left\{V^{b e f o r}\right. \\
\text { ted signific }\end{array}$ & $\begin{array}{l}\text { fore }=v^{\text {bef }} \\
\left.{ }^{\text {ree }}{ }_{i}\right\} P\left\{V^{c}\right. \\
\text { vel of } \alpha\end{array}$ & $\begin{array}{l}\left.V^{\text {after }}=v^{\text {after }}{ }_{i}\right\}= \\
\left.=v^{\text {after }}{ }_{i}\right\} \text {, where } \\
5 \text { and fourfold } \\
\text { th the adopted }\end{array}$ \\
\hline
\end{tabular}

The values in boldface in Table 3 are the non-positive results of statistical tests, which do not support rejection of null hypothesis $H_{0}$ that the tested features i.e., upstream and downstream speeds belong to the same population.

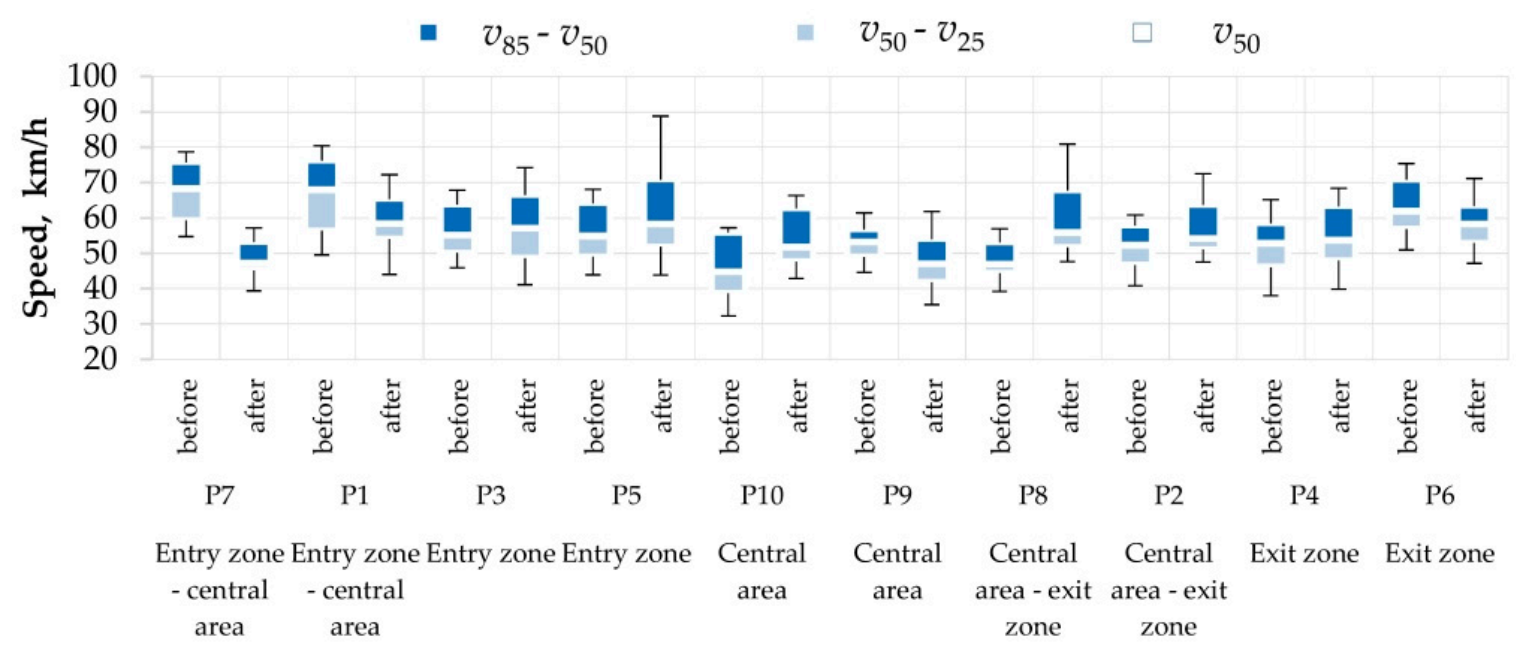

Test sections under analysis

Figure 7. Distribution of speed parameters on the test sections in the range of percentile speeds: $v_{85}-v_{50}$ and $v_{50}-v_{25}$.

According to the results of statistical tests compiled in Table 3, in some cases we deal with different populations. In the case of the effect of pedestrian refuges on the upstream and downstream speeds the results of statistical tests for free-flow and stable-flow traffic conditions were not always the same. Also, for the same type of traffic, the results of the respective statistical tests were heterogeneous. Such test results can be attributed to various factors influencing the motorists' behaviour in free-flow and stable-flow traffic. In order to enhance perceptions of the results, in Figure 7 they are presented in relation to different speed percentiles and distribution bars in the order of sitting along the road stretch in the village. The analysis of the data presented in Table 3 and in Figure 7 showed that there are a number of factors, in addition to the geometric parameters of the pedestrian refuge, that can have a bearing on the vehicle speeds, including positioning along the road stretch, type of the surrounding environment, distance to the nearest buildings and view of the road ahead. Therefore, a number of 
different factors will be taken into account in the analysis of the traffic-calming effect of pedestrian refuges using the methodology presented in Figure 8 to determine the probable main determinants of the calculated speeds and their reduction.

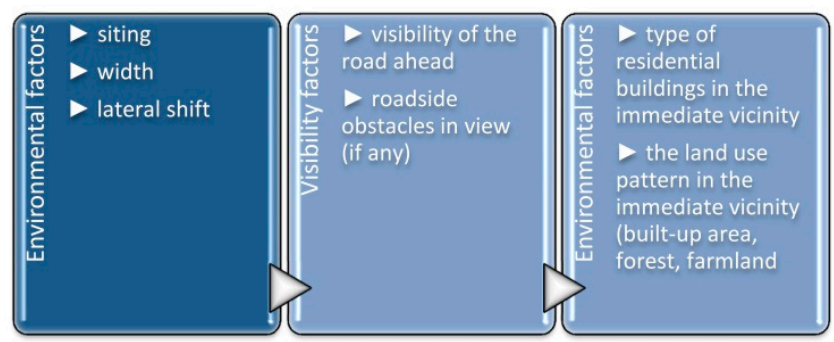

Figure 8. Method of analysis and general and detailed factors under analysis.

\section{Results}

\subsection{Analysis of the Pedestrian Refuge Approach Speeds (Upstream Speeds)}

Taking into account the recommendations of $[1,5]$ that retrofitting of pedestrian refuge scan have a speed reducing effect and improve the safety of vulnerable road users on their way across the street, as the first step the authors analysed the speeds measured upstream of the pedestrian refuge $v^{\text {before }}$. The analysis of the values of $v^{\text {before }}$ given in Table 2 showed that in no case was the 85th percentile of free-flow speed smaller than $50 \mathrm{~km} / \mathrm{h}$, i.e., the speed limit in residential areas. According to the mentioned guidelines [5] the pedestrian refuges should be located where warranted and their geometry should induce reduction of vehicular speed to $50 \mathrm{~km} / \mathrm{h}$ and less. This requirement is not satisfied by the pedestrian refuges under analysis. However, the average free-flow and stable-flow speeds on the test sections No. P8 and P10 were smaller than $50 \mathrm{~km} / \mathrm{h}$.

Taking this into account, the authors analysed also the percentages of vehicles travelling with speeds of $\leq 50 \mathrm{~km} / \mathrm{h}$ and $>50 \mathrm{~km} / \mathrm{h}$ and the results of this analysis are presented in Figure 9 . Figure 9 gives also information if the test section is located before or after the pedestrian refuge, i.e., in the entry zone, village centre or exit zone. On the left side of Figure 9, there are test sections situated before the pedestrian refuges positioned in the entry zones and in the village centres and on the right side, there are four test sections located at the border of or within the exit zones. Two test sections-P1 and P7 were located at the border between the entry zone and village centre and, similarly, two sections-P2 and P8 were located at the border of the village centre area and the exit zone and, hence, different designations have been used for them depending on the direction of traffic, before and after the pedestrian refuges in question. The analysis of percentage data showed that only on two test sections, namely P8 and P10 the percentages of speeds below $50 \mathrm{~km} / \mathrm{h}$ limit before the island locations were ca. $67 \%$ or $75 \%$. The approach speeds obtained in the other cases were much higher. With the purpose to establish which determinants could have a predominant effect on the speed measured before the pedestrian refuge or on the percentage of speeds $\leq 50 \mathrm{~km} / \mathrm{h}$ Figure 9 presents the relevant characteristics of each pedestrian refuge including its sitting along the road stretch, the surrounding environment, residential buildings and view of the road ahead. For identification of determinants, the test sections in Figure 9 have been put in order of increasing percentage of speeds smaller or equal to $50 \mathrm{~km} / \mathrm{h}$ in both parts of the chart. 


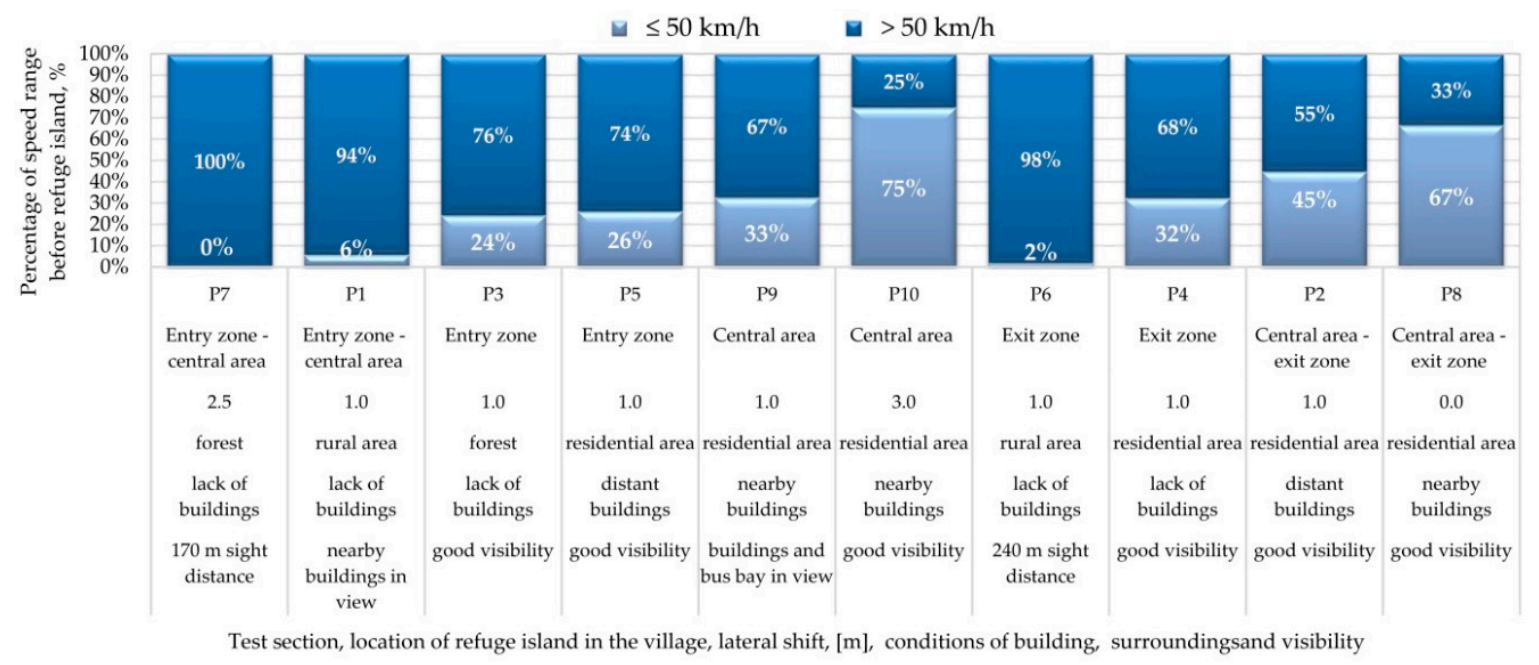

Figure 9. Percentages of the speed ranges before the pedestrian refuges.

Analysing the data presented in Figure 9 above and the features related to the pedestrian refuge siting, surrounding environment and visibility conditions we see that smaller speeds are not directly related to the proximity of residential buildings or view of the road ahead. Only in one case with residential buildings in close proximity where the greatest, $3 \mathrm{~m}$ lateral shift in the travelway alignment (P10) was imposed by the pedestrian refuge the approach speeds were the smallest among all the speeds measured before the pedestrian refuges (Table 2), accompanied by the greatest percentage of speeds smaller or equal to $50 \mathrm{~km} / \mathrm{h}$ (Figure 9). Similar approach speeds and percentage of speeds smaller or equal to $50 \mathrm{~km} / \mathrm{h}$ were recorded on the test section No. P8 with no lateral shift in the travelway alignment, where the approach section was on a horizontal curve running close to residential buildings. One of the smallest approach speeds was recorded on the test section P7 where $2.5 \mathrm{~m}$ lateral shift was imposed, accompanied by the smallest percentage of speeds smaller or equal to $50 \mathrm{~km} / \mathrm{h}$. This allows us to state that the width of the pedestrian refuge and the associated lateral shift in the travelway alignment are not the sole determinants of speeds at which the motorists approach the pedestrian refuges.

The field results presented in Table 2 and in Figure 9 were analysed to establish probable determinants that can, in combination, influence the speeds measured before the pedestrian refuges. These determinants, relating to the pedestrian refuges located in the entry zones and in village centre areas are presented in Figure 10a. Therefore, the determinants presented in Figure 10a should be taken into account when siting the pedestrian refuges in the entry zones and this, in combination with appropriate engineering and traffic planning, should result in obtaining approach speeds not exceeding the speed limit in residential areas. Figure 10b, in turn, presents the determinants in relation to the road sections before the pedestrian refuges located in the exit zones.

Summarizing the above analyses we can state that the factors that should be taken into account when siting a pedestrian refuge include both the features of the approach section and the arrangement of residential buildings in the immediate vicinity, as these are the primary factors determining the approach speed and the safety of pedestrians travelling across the street through the crossing in question. Thus, the authors believe that, in light of the above facts, in order to ensure that the approach speeds do not exceed the speed limit in residential areas $(\leq 50 \mathrm{~km} / \mathrm{h})$ it is necessary to modify the pedestrian refuges design or thoroughly re-consider the traffic management arrangements. The analyses carried out in this research allow us to conclude that a typical pedestrian refuge imposing $1 \mathrm{~m}$ lateral shift on both sides, sited in the exit zone, surrounded by farm fields or open space without residential buildings in close proximity is not an effective measure and does ensure approach speeds smaller or equal to $50 \mathrm{~km} / \mathrm{h}$. 


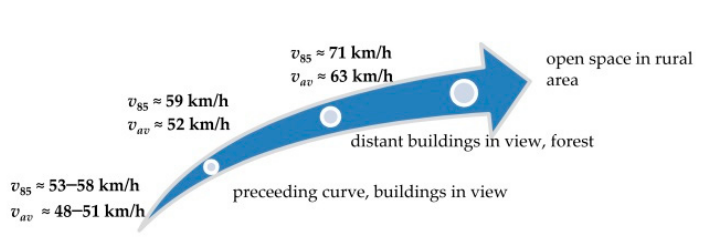

(a)

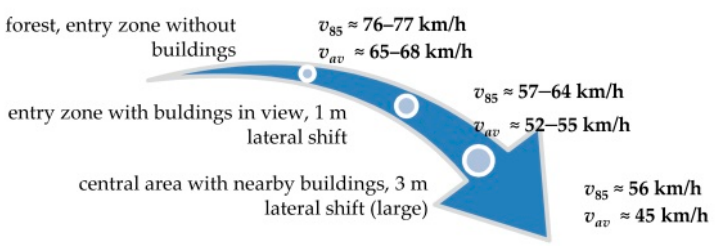

(b)

Figure 10. Determinants of the approach speed depending on the pedestrian refuge location: (a) in the entry zone or in the village centre; $(\mathbf{b})$ in the exit zone.

\subsection{Comparison of the Pedestrian Refuge Approach Speeds Obtained in This Research with the Results} Obtained by Other Researchers

In order to compare the results obtained in this research with the results obtained by other researchers the authors have redrawn the graph relating the speed reduction to the speed value after the central island (Figure 11) published in [14] replacing the shape and width of the central island with the width of pedestrian refuge island. This allowed comparing the results of the research project on German roads published in [14] with the results obtained by the authors in villages located on regional roads in Poland in the vicinity of pedestrian refuges. The results of this comparison are presented in Figure 12. Lateral shift in the travelway alignment was the main factor considered in this case. The research results given in [13] concerned the effect of lateral shift generated by the gateway island on the speed of vehicles after the island, the objective being to achieve reduction of the speed of vehicular traffic in the entry zone by using different types of horizontal deflection measures imposing different lateral shifts. Figure 12 presents the schematic diagrams of the analysed pedestrian refuges accompanied with the typical pavement markings.

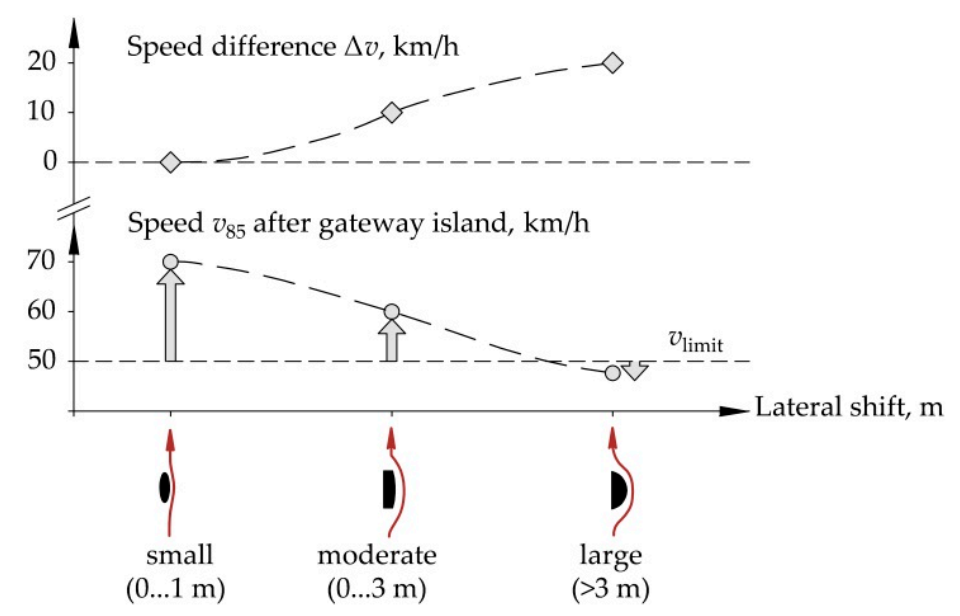

Figure 11. Relationship between the speed parameters $\Delta v_{85}$ and $v_{85}$ after the gateway island and the lateral shift (redrawn from Wirksamkeit geschwindigkeitsdämpfender Maßnahmen außerorts, 1997 [14], p. 9). 


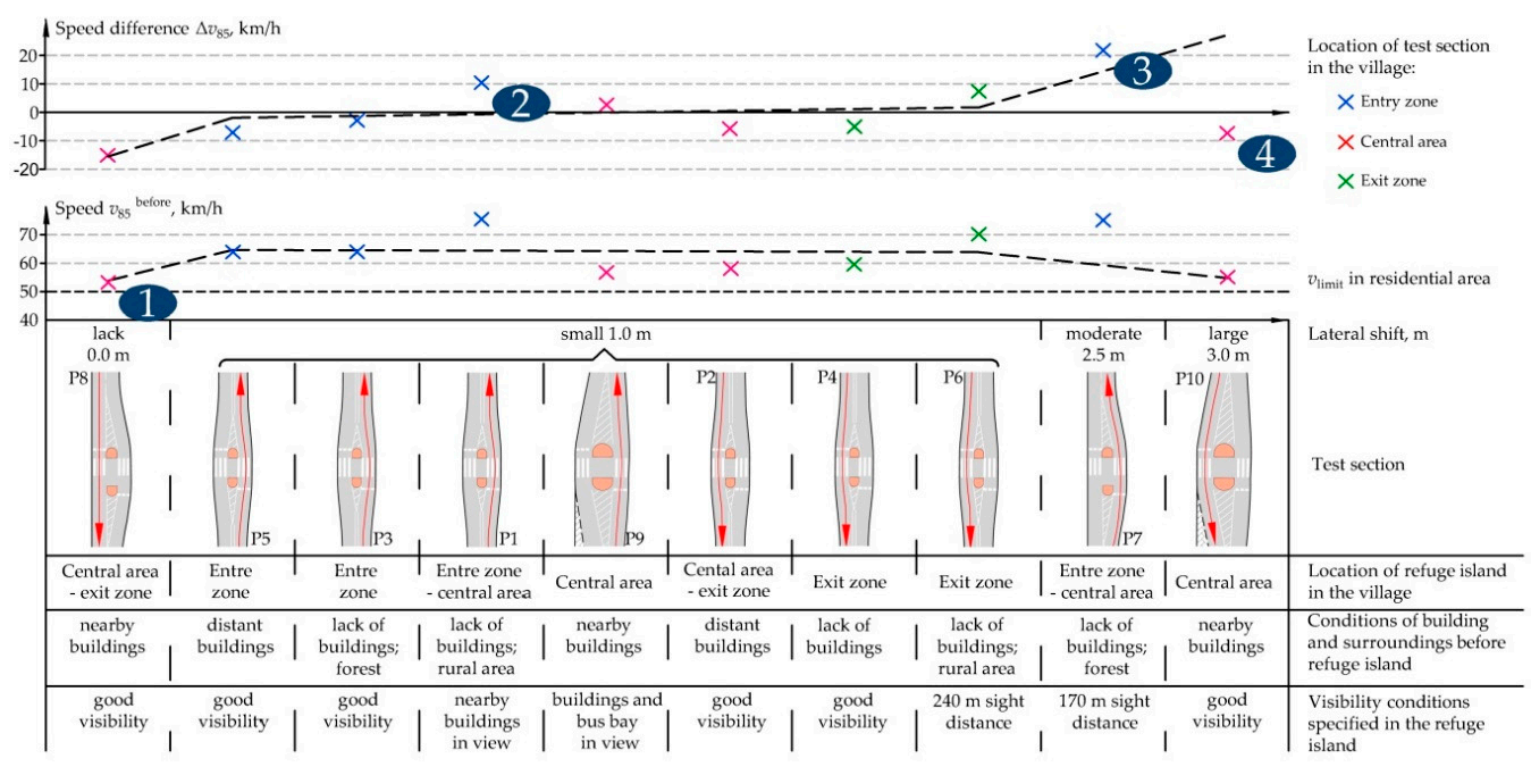

Figure 12. Relationship between the speed parameters: $\Delta v_{85}$ and $v_{85}$ before the pedestrian refuge and the lateral shift.

Comparing the test results presented in Figure 12 we see that in the entry zones without footways, nearby residential buildings and other such features, pedestrian refuges do not ensure achieving the desired speed reduction, and this irrespective of the approach speed (Figure 3a). Driving with speeds higher than $50 \mathrm{~km} / \mathrm{h}$ in built-up areas can be explained by good visibility conditions without any buildings or side obstacles in view. The desired speed reduction of $\Delta v_{85}=10-20 \mathrm{~km} / \mathrm{h}$ is obtained if there are nearby residential buildings, footways, private entries in view (Figure 5a) within a close distance from the pedestrian refuge (up to $100 \mathrm{~m}$ ).

Unfortunately, appearance of residential buildings in close proximity does not, on its own, have a determining effect on motorists driving at speeds much exceeding the limit of $50 \mathrm{~km} / \mathrm{h}$. The authors believe that there are a number of factors relevant to the degree of speed reduction, including, without limitation, the lateral shift, refuge shape (symmetric or adjacent to the road centreline), distance to the nearest residential buildings, visibility conditions before and after the refuge, rather than the lateral shift being one and only factor, as it could be concluded from the research results presented in Figure 11.

Referring to pedestrian refuges located in the entry zones we can conclusively state that they fail to impose the desired reduction of the upstream speed to $\leq 50 \mathrm{~km} / \mathrm{h}$ irrespective of the speed of the vehicle in the exit zone (Table 2 and Figure 12). Reduction of vehicular speeds in the exit zone was noted only in the case when the sight distance after the pedestrian refuge was ca. $240 \mathrm{~m}$ (Figure 4b). In this case speed reduction of $\Delta v_{85}=\mathrm{ca} .7 \mathrm{~km} / \mathrm{h}$ was obtained, yet attention is drawn to the pedestrian refuge approach speeds much exceeding the speed limit in residential areas $(50 \mathrm{~km} / \mathrm{h})$, this attributed to approach section characteristics i.e., $750 \mathrm{~m}$ long straight section of the road surrounded by farm fields devoid of residential buildings in close proximity. These approach conditions are the main determinant of the high speeds before the approach with the value of $v_{85}$ before $=$ ca. $71 \mathrm{~km} / \mathrm{h}$ which is much above the speed limit in residential areas in Poland. Sight distance was, in turn, the main determinant of the recorded speed reduction. In another case, the pedestrian refuge located in the exit zone was preceded by a long straight section (Table 1) of the road with distant, loosely spaced residential buildings (Figure $3 b$ ).

The smallest approach speeds were noted on the departure lane with no lateral shift (Figures $5 \mathrm{~b}$ and 12). However, it must be noted that the approach section followed a winding route with residential buildings in close proximity continuing up to $80 \mathrm{~m}$ before the refuge location. The authors believe that the above-described approach conditions were, in this case, the main determinant of the recorded smaller approach speeds rather than the pedestrian refuge installed on the opposite lane. On the 
other hand, after the pedestrian refuge, the greatest of all increase of speed was noted (Table 2), this attributed to the surrounding environment-a forest devoid of any residential buildings (Figure $5 b$ ).

\subsection{Summary of the Analyses of Pedestrian Refuge Approach Speeds}

Taking this into account, and considering the pedestrian refuge design proposed in [5], the authors are of the opinion that pre-warning devices (thermoplastic strips) or rumble strips should be installed ca. $70 \mathrm{~m}$ from the pedestrian refuge axis to alert the motorists of the obstacle ahead. Moreover, the road authority should consider putting up before the pedestrian refuge the B-33 (speed limit) and B-25 (no overtaking) road signs, depending on the needs and the local conditions. The need for the "no overtaking" sign was noted by the authors during the research in the case of pedestrian refuges adjacent to the road centreline where the speeds of travel on the opposing traffic lane (with no lateral shift) much exceeded $80 \mathrm{~km} / \mathrm{h}$. These cases were not singular or even rare. The decision whether or not to put up the speed limit sign depends not only on the speeds in the village centre but also on the siting of the pedestrian refuge in relation to the existing access and public buildings layout.

It must be noted that in the cases under analysis the speeds of travel were much above the speed limit in residential areas, except for two cases where free-flow and stable-flow speeds below $50 \mathrm{~km} / \mathrm{h}$ were obtained (Figure 12). In the first case there was a winding approach section with buildings located in close proximity with no lateral shift (Figure $5 b$ ) and in the other case the travelway alignment was shifted by $3 \mathrm{~m}$ and the asymmetric design of the island was visible to the motorist approaching it through a straight section (Figure $6 \mathrm{~b}$ ).

\subsection{Analysis of the Pedestrian Refuge Departure Speeds}

Reduction of vehicular speeds at pedestrian refuges is indirectly related to the issue of obtaining speed reduction also after the island. While the design of pedestrian refuges, as the primary objective, should enforce reduction of vehicular speeds right before and alongside the pedestrian refuge [5], it becomes interesting from the research viewpoint to check their effect on the speed on the analysed stretch of road in the village area. As such, the authors carried out similar analyses for speeds measured after the pedestrian refuges, the results of which are given in Table 2 and in Figure 13, including short descriptions of the relevant factors. Additionally, Figure 13 shows the percentages of motorists not obeying the speed limit in residential areas, as measured after the pedestrian refuges.

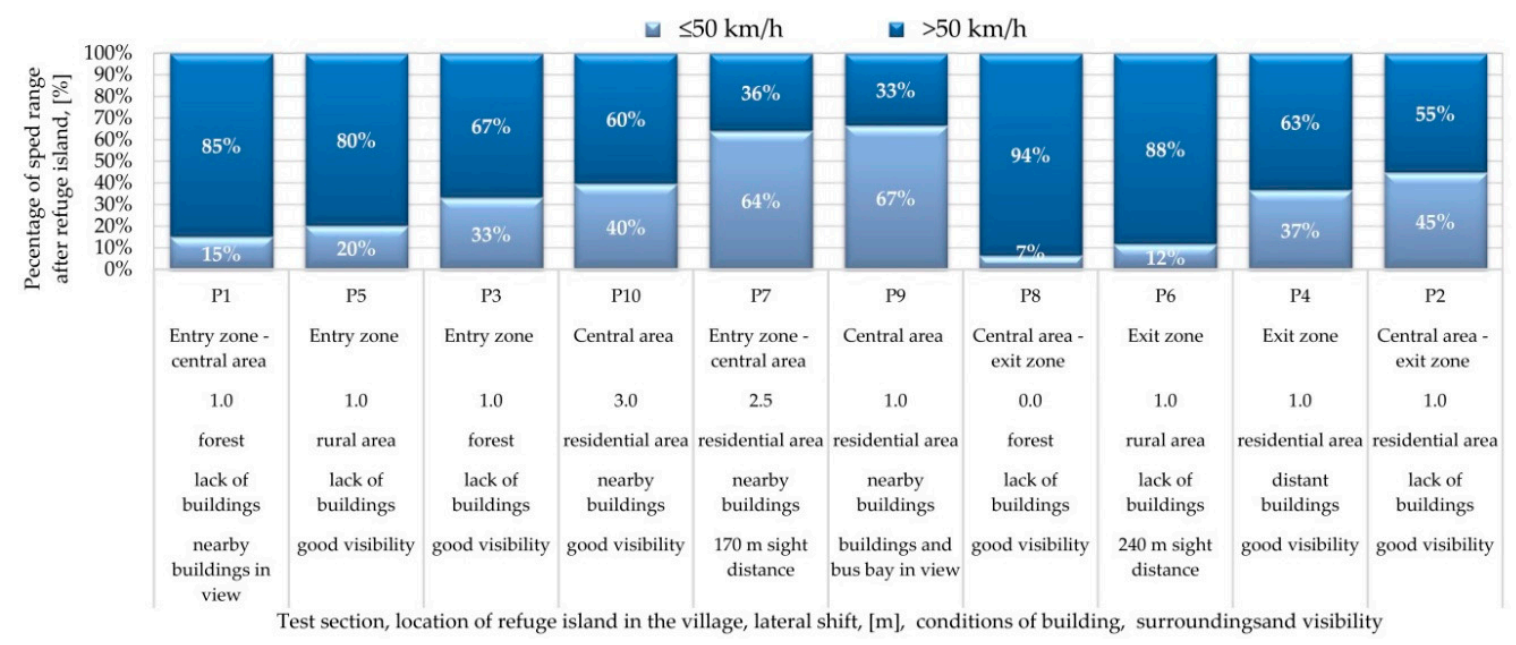

Figure 13. Percentages of a speed ranges after the pedestrian refuges.

The analysis of the data given in Table 2 and in Figure 13 shows that the pedestrian refuges failed to enforce reduction of $\mathrm{v}_{85}$ speed to below $50 \mathrm{~km} / \mathrm{h}$, i.e., the speed limit in residential areas and, furthermore, the speeds downstream of the pedestrian refuges do not depend on the lateral shift in the travelway alignment. Only in two cases (P7 and P9) the average free-flow and stable-flow speeds were 
much below the speed limit in residential areas. The determining factor, in this case, was the distance to residential buildings, the type of surrounding environment alongside the road and sight distance after the pedestrian refuge (Figure 14a). However, in the authors' opinion, the most important factor, in this case, is the view of the end treatment of the pedestrian refuge and the lateral shift in relation to the departure lane alignment.

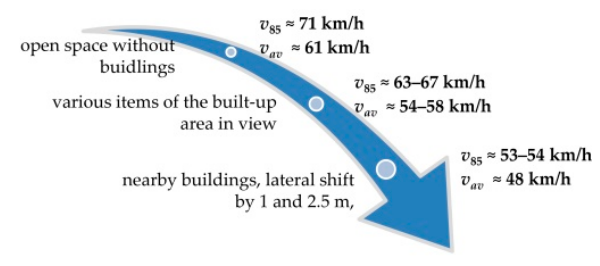

(a)

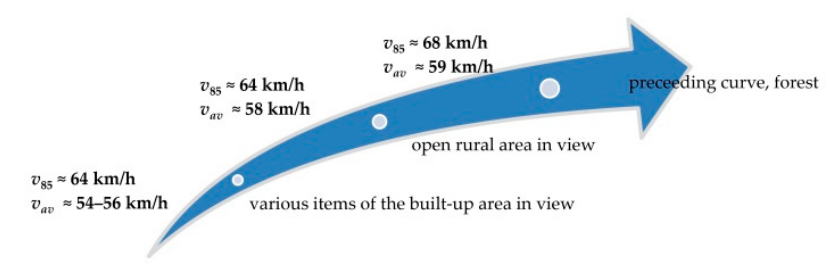

(b)

Figure 14. Determinants of the departure speed depending on the pedestrian refuge location: (a) in the entry zone or in the village centre; $(\mathbf{b})$ in the exit zone.

The speeds recorded on the section after the pedestrian refuge located in the entry zone were much above the speed limit in residential areas. These very high speeds were, in this case, most probably caused by a combination of factors: very long sight distance and nature of the surrounding environment with farm fields, forest and lack of residential buildings in close proximity (Figures 3a and $4 a$ ).

In the village centre also the view of the road after the pedestrian refuge, as seen by the driver passing the pedestrian crossing is an important determinant of the speed of travel. If, for example, the pedestrian refuge opens to a wide area of the travel lane and a tangentially positioned open bus bay (Figure $6 \mathrm{~b}$ ) then the drivers, despite a large lateral shift of $3 \mathrm{~m}$ and the lowest speed recorded before the pedestrian refuges, tend to accelerate seeing end of village at a short distance and lack of any obstacles that would make them slow down.

Conversely, if after passing the pedestrian refuge the motorists sees bridge parapets, residential buildings and also raised kerbing, clearly communicating the end of taper and horizontal deflection (Figure 6a) he/she will maintain the speed at more or less the same level or even slow down in relation to the speed upstream of the pedestrian refuge.

By far the greatest determinant of the speed reduction after the pedestrian refuge is the combination of a large lateral shift, with the end of deflection communicated by a high kerb, and nearby residential buildings or bridge parapets in view (Figure 5a).

Similar to the previous case, the authors established the determinants of the vehicle speeds after the refuges located in the village exit zone (Figure 14b). View of the road ahead, as seen by the driver passing alongside the pedestrian crossing is also highly relevant. If the motorists see bus bays, bike paths, distant buildings and does not see the D-42 built-up area sign he/she will generally drive with more or less the same speed as on the approach to the pedestrian refuge. Conversely, if during passing alongside the pedestrian refuge the driver sees the road ahead surrounded by farm fields (Figure 2b) or by a forest (Figure $5 b$ ) with no side obstacles or nearby buildings in view, he/she would accelerate considerably, reaching speeds much greater than on the approach to the pedestrian refuge.

\subsection{Comparison of the Pedestrian Refuge Departure Speeds Obtained in this Research with the Results Obtained by Other Researchers}

Similar to the analysis presented in 5.2 above (Figure 11), for comparison purposes, the departure speeds after the pedestrian refuges were compared with the results of research given in [14]. The results of this comparison are presented in Figure 15. Analysing the data in Figure 15 we see that in the case of pedestrian refuges located in the village centre with nearby residential buildings (P7, P9) speed reduction can depend on the lateral shift, yet only in combination with other determinants closely associated with the view of the buildings in proximity and the road section ahead. When buildings are 
located away from the road (sections P1, P4, P5) then the pedestrian refuges cause an increase of speed after the refuge.

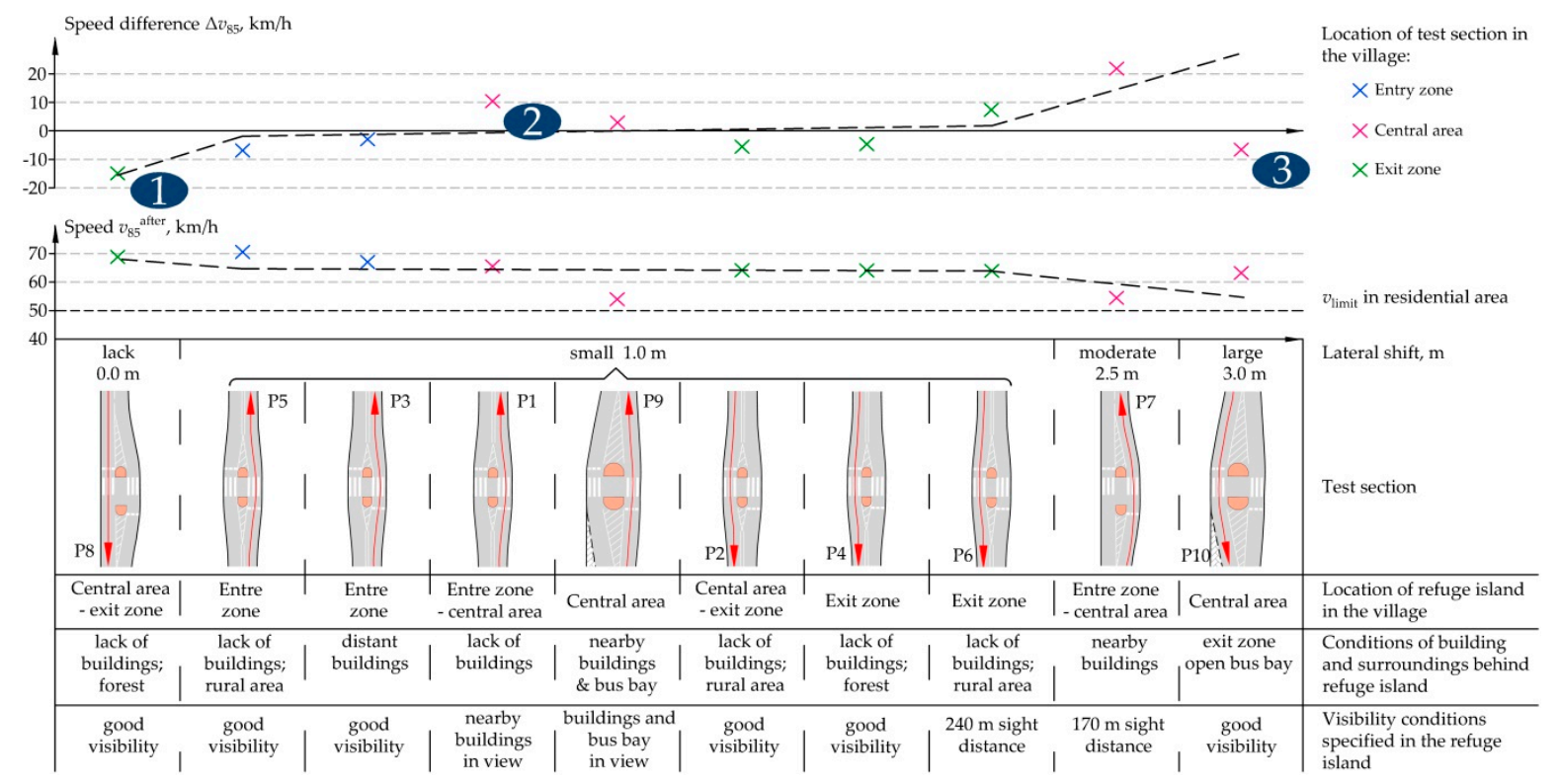

Figure 15. Relationship between the speed parameters: $\Delta v_{85}$ and $v_{85}$ after the pedestrian refuge and the lateral shift.

The only exception to that is the case with an asymmetric pedestrian refuge imposing a $3 \mathrm{~m}$ (i.e., large) lateral shift (P10). With the open bus bay positioned tangentially to the departure lane section, this design, allowing the drivers to overrun the bus bay area provokes them to accelerate (Figure 15). This peculiar layout is not in compliance with good engineering practice since locating these two road elements beside each other is in conflict with the principles of traffic calming and protection of vulnerable road users. What can be stated conclusively is that before the pedestrian refuge and alongside the crossing the 85th percentile speed on the approach section and the average speeds on either side were the smallest of all the measured values, which is attributed to large lateral shift. This is to say that although lateral shift by $3 \mathrm{~m}$ induced speed reduction, this effect was limited to the section of the road before the pedestrian refuge (Figure 11).

Similar observations can be made when comparing the cases with the pedestrian refuges located in the exit zones (Figure 15). When the pedestrian refuge is followed by a section where the buildings, if any, are spaced away from the road (P3, P6), surrounded by farm fields (P2) or a forest (P8), the increase of speed was noted after the pedestrian refuge. Conversely, with much-reduced sight distance, the pedestrian refuge can contribute to speed reduction, the sight distance being then the determining factor.

\subsection{Summary of Analyses of Pedestrian Refuge Departure Speeds}

In the analysed cases, the departure speeds and the speed difference across the pedestrian refuge can be influenced by a combination of factors including the lateral shift, sitting along the road stretch, distance to the nearest buildings and visibility conditions.

The authors suggest placing safety barriers, barrier bollards or street furniture items in the vicinity of pedestrian refuges, as per the recommendation of [5]. In accordance with [5] these items should be positioned after the island up to the end of $\mathrm{P}-21$ hatched marking. In the opposite direction these items should be installed on a min. $70 \mathrm{~m}$ long section, that is up to the pre-warning device. These measures would probably increase the reduction of the speed value before the pedestrian refuge with the effect maintained on the section past the island. 


\subsection{Analysis of Speed Variation at the Pedestrian Refuge}

The second parameter defining the speed reducing performance of the pedestrian refuges for the approach and departure speeds is the speed reduction alongside the pedestrian refuge. The obtained speed differences are presented in Figure 16, together with a description of developments in the vicinity of the pedestrian refuge and view of the road ahead. From the data presented in Figure 16 it transpires that the main determinants of obtaining the desired speed reduction are the surrounding environment of the pedestrian refuge and view of the road ahead, i.e., accurately communicated information in the driver's field of view. The issue of the driver's perception of the information present in the visual field is studied in [11,12] and the issue of perception of the information given on the new generation traffic signs is covered in [10].

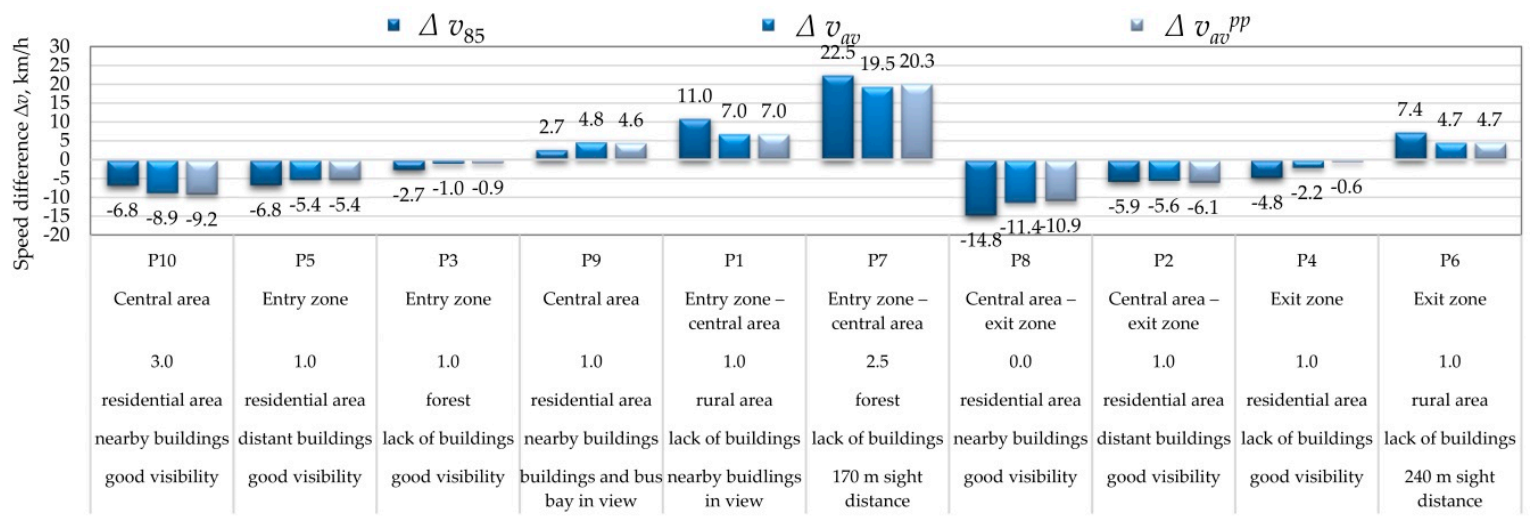

Figure 16. Speed variation on the road section alongside the pedestrian refuge (the sight distance is given in relation to the pedestrian refuge axis).

Lateral shift by $3 \mathrm{~m}$ (P10) which was the greatest of all the cases, in combination with good visibility and accessible open bus bay area instead of making the drivers slow down encouraged them to accelerate, both in free-flow and stable-flow conditions. The situation is similar on the two remaining test sections imposing lateral shift by $1 \mathrm{~m}$ on both sides with different surrounding features: distant residential buildings- $\mathrm{P} 4$ and farm fields in the village centre- $-\mathrm{P} 5$ where the motorist had a good view of the road ahead.

Speed reducing effect was confirmed on the three other test sections-P1, P7 and P9, with residential buildings in close proximity and different sight distances. The greatest speed reduction was recorded in the case of asymmetric lateral shift in the travelway alignment by $2.5 \mathrm{~m}$, yet this should be attributed to the bridge in view and houses in close proximity of the road rather than to the lateral shift and the pedestrian refuge on one side of the road centreline. The probable determinants of speed variation alongside the pedestrian refuges located in the entry zones or village centres and in the exit zones are presented in Figures 17a and 17b respectively. Similar cases, with the speeds after the pedestrian refuges greater than before were noted on the sections in exit zones (test sections P2, P3 and P8) with good visibility of the road ahead and where the exit section was surrounded by forest rural area or built-up area, yet with buildings located far away from the road. Significant reduction of vehicular speeds was noted only when the motorists approached the fragment of the road giving shorter sight distance (P6). 


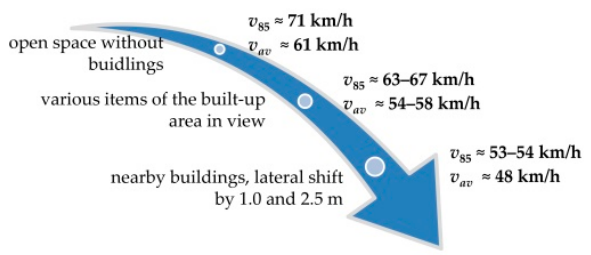

(a)

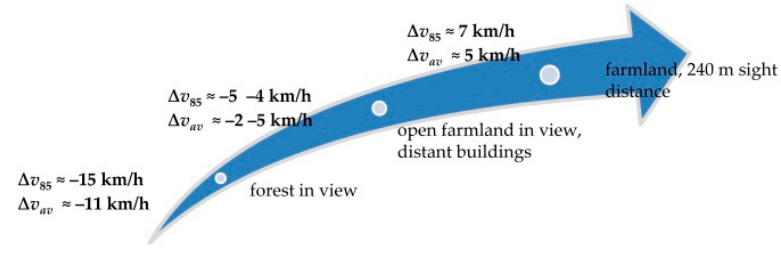

(b)

Figure 17. Determinants of the variation of speed at pedestrian refuges located: (a) in the entry zone or in the village centre; (b) in the exit zone.

Similar relationships and determinants can be found when calculating the speed variation ratio which is a parameter directly related to the above factors. Moreover, the same determinants are confirmed, as presented in Figure 17.

\section{Validation of the Results of Analyses with the Speed Data Obtained on a Test Section Including Post-and-Chain Barriers}

\subsection{Analysis of the Speed Reduction Obtained by Retrofitting Post-and-Chain Barriers along the Regional Road Stretch}

In none of the cases described in point No. 5 above did the test section include side obstacles such as post-and-chain barriers, barrier bollards or street furniture items. Taking this into account, in this section, the authors refer the results of the tests carried out in Wrzosowo, originally published in [15]. The measures provided in the entry zone of the analysed village included semi-circular islands on one side of the centreline, imposing lateral shift by $5 \mathrm{~m}$ and B-33 speed limit signs imposing $40 \mathrm{~km} / \mathrm{h}$ speed limit on the road section with residential buildings located in the close proximity. Notwithstanding these measures, the free-flow speeds were higher than the speed limit in residential areas and much higher than the speed limit posted on the B-33 sign. Therefore, post-and-chain barriers were retrofitted alongside the road to protect the pedestrians on the section where the buildings are located close to the road (Figure 18). With the post-and-chain barriers in place, the traffic conditions were re-tested by the authors and the results (Figure 19) confirmed that this has considerably improved the situation on the road, reducing the average free-flow speed to below the speed limit posted on the B-33 sign.

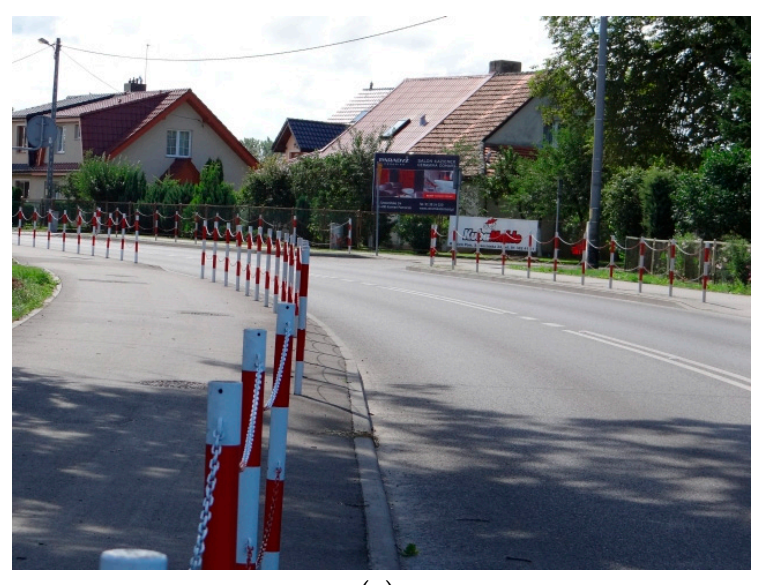

(a)

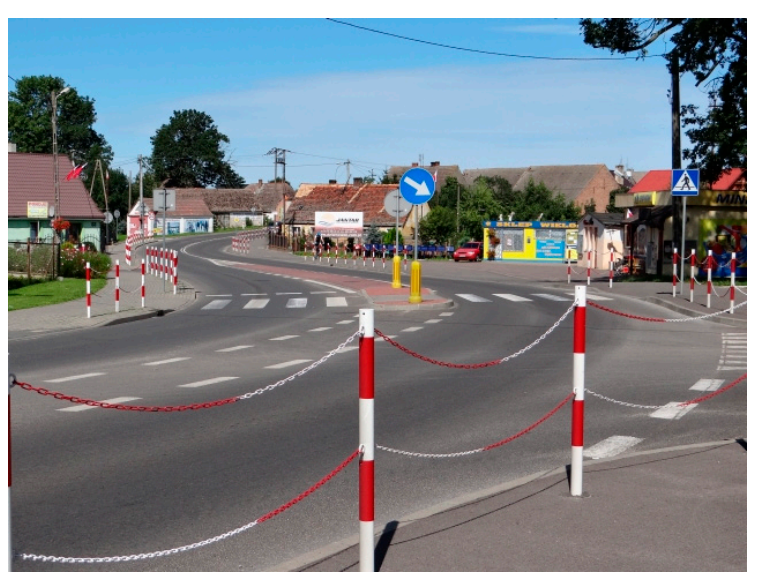

(b)

Figure 18. Stretch of the regional road lined with post-and-chain barriers: (a) in the village centre; (b) at the pedestrian crossing. 


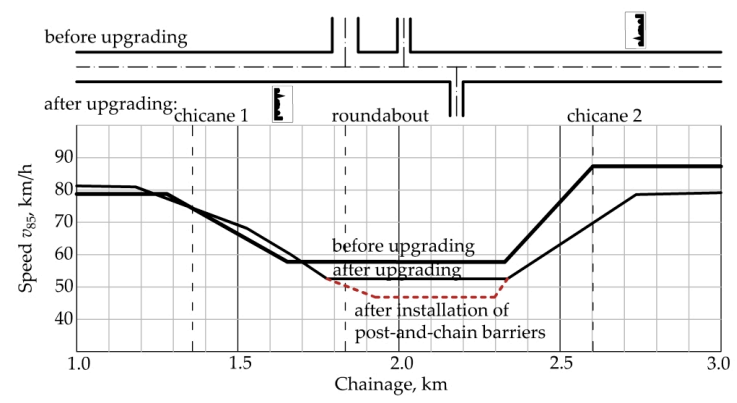

(a)

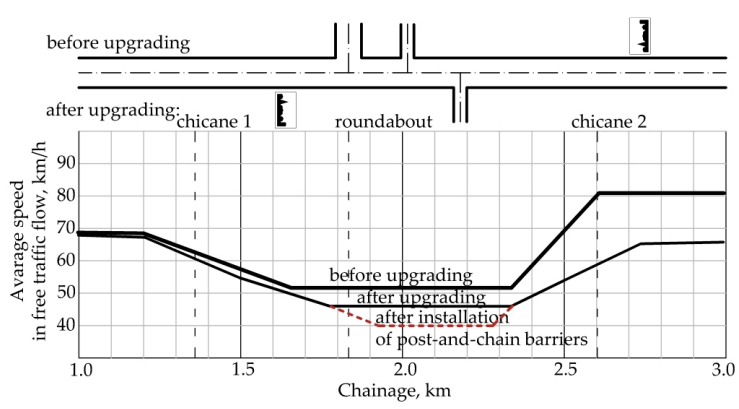

(b)

Figure 19. Free-flow speed profiles before and after upgrading of the regional road section in the village area (drawings by D. Kacprzak and A. Sołowczuk [15]): (a) $v_{85}$ speed profile; (b) $v_{a v}$ speed profile.

\subsection{Comparison of Speeds Measured before and after Installation of Post-and-Chin Barriers at the Pedestrian Refuge}

With the purpose to examine the effect of the post-and-chain barriers installed in the built-up area alongside the section actually occupied by buildings, yet without the speed limit sign B-33, comparative surveys were carried out in the nearby village Wrzosowo Osiedle at the pedestrian refuge located in the village centre area. There the pedestrian refuge generates symmetrical lateral shift by $1.0 \mathrm{~m}$, the same for both directions of traffic, includes 1:15 tapered markings and both the travel lanes are 3.5 wide.

The speeds measured for both directions of traffic are presented in Figures 20 and 21. The analysis of the data given in Figures 20 and 21 showed that after upgrading the speeds exceeded the speed limit in residential areas $(50 \mathrm{~km} / \mathrm{h})$ in both directions of traffic. On the other hand, installation of post-and-chain barrier-imposed reduction of the average free-flow and stable-flow speeds to below $50 \mathrm{~km} / \mathrm{h}$ (Figures 21 and 22). Also, the free-flow 85 percentile speed decreased, and decreased much, and although it exceeded the limit of $50 \mathrm{~km} / \mathrm{h}$ both before and after the pedestrian refuge, the calculated values are by ca. $10 \mathrm{~km} / \mathrm{h}$ lower than their counterparts before installation of the post-and-chain barriers. This confirms a major effect of the installed post-and-chain barriers in reducing the speeds of traffic. Figure 21 compares the percentages of the analysed speeds before and after installation of post-and-chain barriers on both sides of the road. The percentage of speeds smaller or equal to $50 \mathrm{~km} / \mathrm{h}$ is much greater after installation of the post-and-chain barriers, as compared to this percentage after upgrading, yet without the barriers in place (see Figure 21).

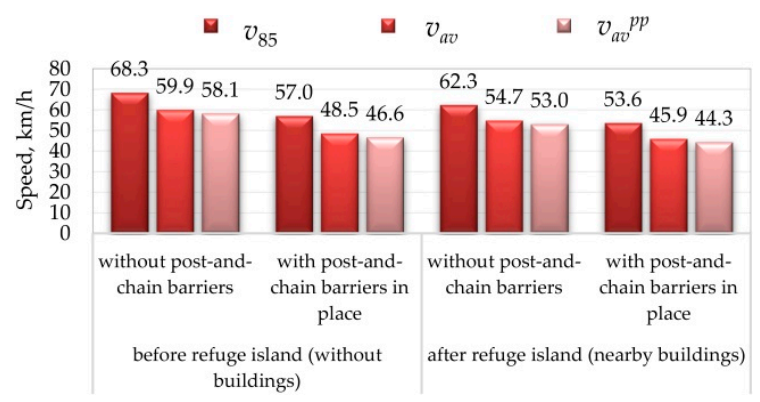

(a)

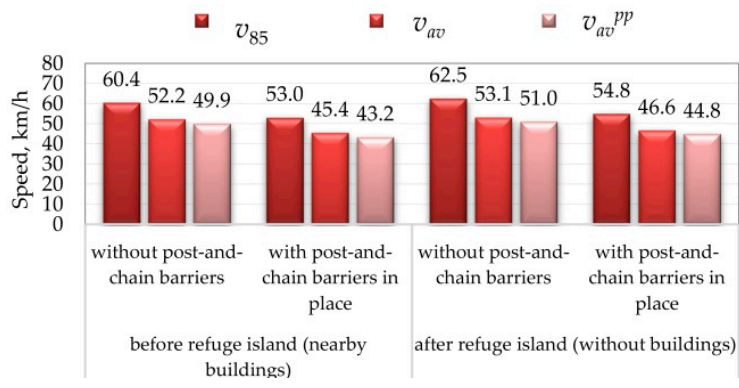

(b)

Figure 20. The speed distribution parameters before and after the pedestrian refuges on the test sections with sight distances of: (a) 200 m; (b) 140 m. 


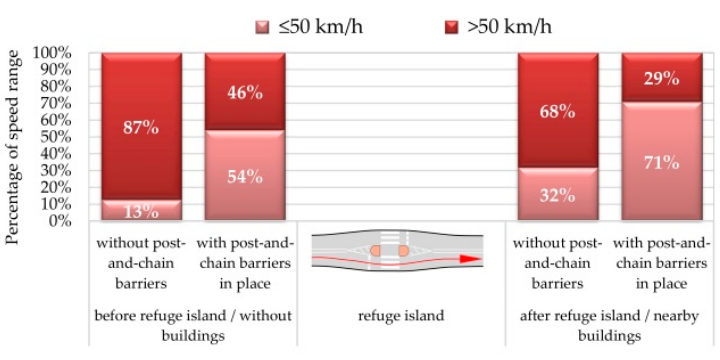

(a)

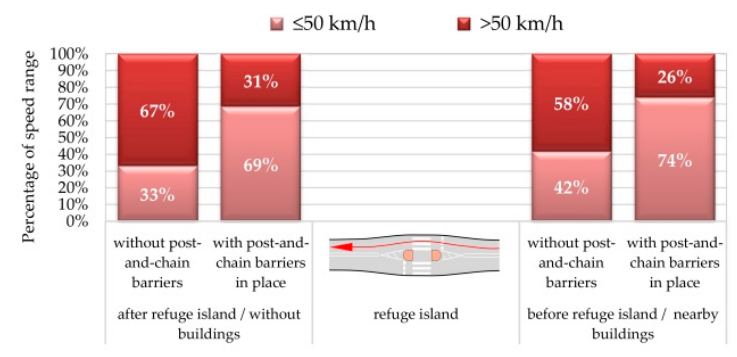

(b)

Figure 21. Calculated percentages of $\leq 50 \mathrm{~km} / \mathrm{h}$ and $>50 \mathrm{~km} / \mathrm{h}$ speeds on test sections under analysis with sight distances of: (a) $200 \mathrm{~m}$; (b) $140 \mathrm{~m}$.

The analysis of the data resented in Figure 21 showed that retrofitting of the post-and-chain barriers influenced the drivers' behaviour making them slow down to below the speed limit in residential areas $(50 \mathrm{~km} / \mathrm{h})$ on the road section concerned. The surrounding environment of the approach section to the pedestrian refuge was found to be also relevant in this case. In the case of approach section surrounded by a forest and post-and-chain barrier limited to a short section preceding the pedestrian refuge, the percentage of speeds $\leq 50 \mathrm{~km} / \mathrm{h}$ was smaller before (54\%) than after the pedestrian refuge $(71 \%)$ where the drivers could see the road section lined with post-and-chain barriers over the length of $200 \mathrm{~m}$ (Figures 20a and 21a).

A different speed distribution was obtained with the approach section located in the built-up area, yet without buildings in close proximity (Figures 20b and 21b). In the case under analysis, most drivers (up to $74 \%$ ) approached the pedestrian refuge at speeds smaller or equal to $50 \mathrm{~km} / \mathrm{h}$ and accelerated after passing the island having in view a road section surrounded by a forest without any buildings (Figure 21b).

\subsection{Comparison of Speed Reductions before and after Retrofitting the Post-and-Chain Barriers}

Before installation of the post-and-chain barriers a big value of speed reduction was recorded in one case (Figure 22) for one direction of traffic only. The approach section in this case was surrounded by forest groves (Figure 23a) and residential buildings started after the pedestrian refuge, and they were situated not by the footway but spaced away from the road. The drivers were given good visibility with the curve to the right, after which the view was reduced, located ca. $200 \mathrm{~m}$ after the pedestrian refuge (Figure 23a). It is probably the combination of the above-mentioned conditions that resulted in such a big reduction in speed alongside the pedestrian refuge. Although installation of post-and-chain barriers brought speed reductions only half as big as previously, it must be underscored that both the upstream and downstream speeds were much smaller than before their installation (Figures 20 and 21).

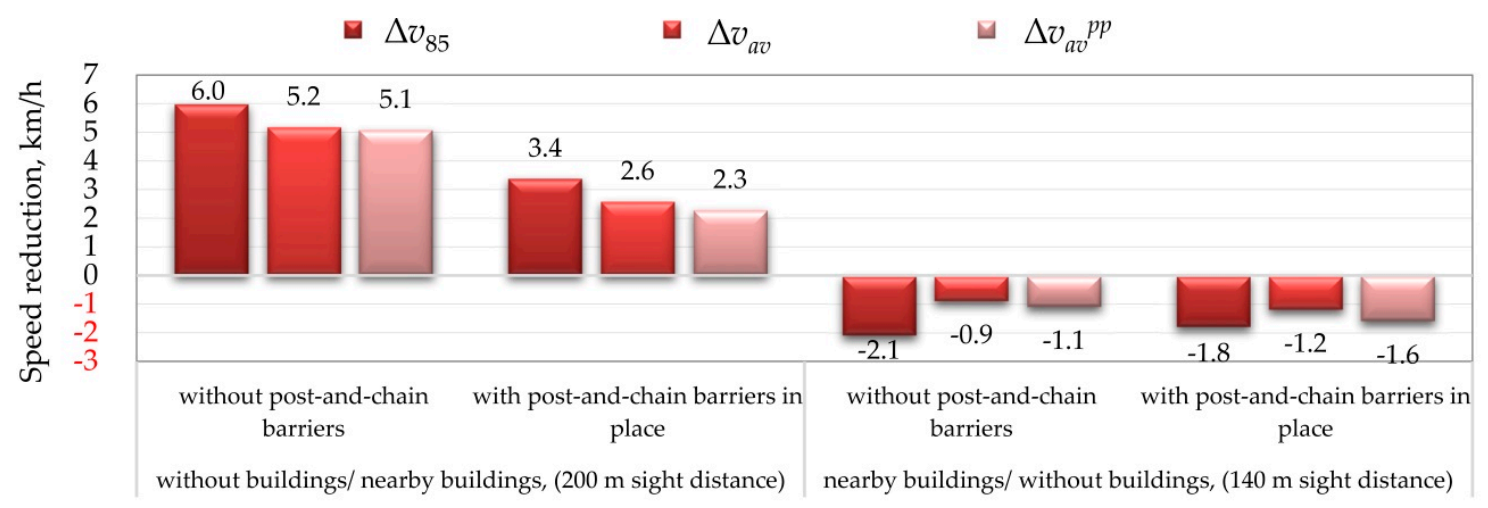

Figure 22. Speed differences on the analysed test sections. 


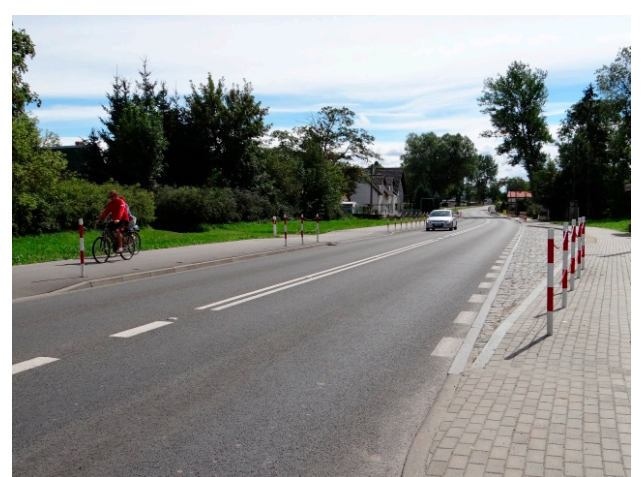

(a)

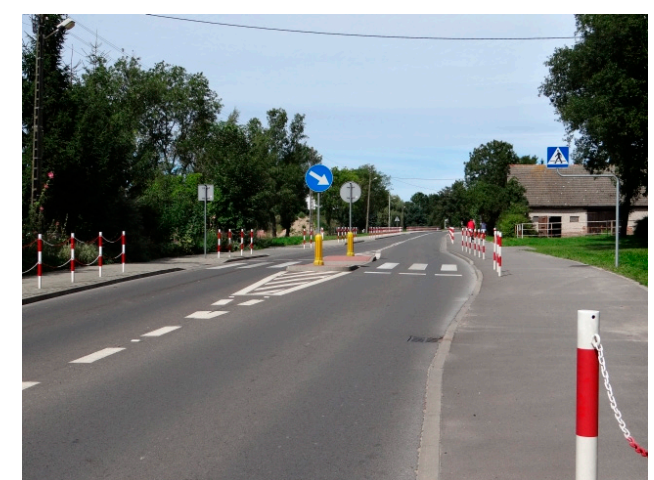

(b)

Figure 23. Sight distance after the pedestrian refuge: (a) $200 \mathrm{~m}$; (b) $140 \mathrm{~m}$.

Conversely, on the test sections with the opposite direction of traffic, with shorter sight distances and nearby buildings situated alongside the approach section, where the driver could see the further course of the road surrounded by forest groves no sooner than after passing the pedestrian refuge (Figure 22) the drivers tended to accelerate rather than slow down (Figure 22). The analysis of results shows that speed reduction is obtained by a combined effect of the surrounding environment of the pedestrian refuge approach section and visibility of the surrounding environment of the road section downstream of the pedestrian refuge.

Note, however, that speed difference is purely an analytical parameter, the objective being reduction of free-flow and stable-flow speeds to below the speed limit in residential areas, which was achieved in this case owing to the retrofitted pedestrian refuge and post-and-chain barriers as the primary factors. The authors believe it is a correct approach to consider the speed values as the most important parameter rather than the calculated speed reductions.

\section{Discussion and Proposed Engineering Measures}

The above results confirm possible speed-reducing effect of pedestrian refuges, although there are a number of relevant factors to be considered before deciding about the refuge layout (symmetric or asymmetric) and width, namely: siting of the pedestrian refuge in the village area, nature of the surrounding environment in the planned location, sight distance, room for widening the carriageway, any bus bays in the vicinity. The obtained speed differences show that the lateral shift is not the sole factor determining the level of speed reduction.

The flow chart for selecting the type and width of the pedestrian refuges on regional roads in villages, based on chosen factors, is presented in Figure 24. The authors recommend, following the German guidelines [13], to consider in the entry zones the environmental factors and use symmetrical central islands combined with pedestrian crossings. In open rural areas, ca. 35 long by $6.25 \mathrm{~m}$ wide, symmetric lens-shaped central islands should be used, imposing a large lateral shift in the travelway alignment, passed on a curve with 50 m radius, with min. 3.5 travel lane width, enhanced with barrier bollards and single tree plantings at the pedestrian crossing location (Figure 25a). In forest areas cigar-shaped central islands are recommended, ca. 45 long by $5 \mathrm{~m}$ wide, passed on $\min .3 .5 \mathrm{~m}$ wide travel lanes, enhanced with barrier bollards only (Figure 25b). Additional plantings are not required where the surrounding environment is occupied by a forest. According to the Swedish [8] and German [13] guidelines and taking into account the drivers' perception studies reported in [10-12] the authors indicate a need of interactive road signs to be placed in the entry zones to warn the drivers of the central island and pedestrian crossing located ahead of them (activated by motion sensors).

Based on the results of this research, the authors recommend symmetric pedestrian refuge islands, $2 \mathrm{~m}$ or $2.5 \mathrm{~m}$ wide, the latter to accommodate bicycles, if required, as an appropriate design for the village centre areas. In order to highlight the pedestrian refuge location and influence the driver's perception, it should be accompanied with post-and-chain barriers $[5,7]$ or barrier bollards of various 
colours and sizes, the latter being a popular measure used in the West European countries. Examples of designs used in Poland are presented in Figures 18 and 23. Figure 26, in turn, shows the proposed design including post-and-chain barriers. According to [5] the post-and-chain barriers should extend ca. 10-15 $\mathrm{m}$ upstream of the pedestrian refuge, measuring from the end of the hatched marking and at least to the end of the hatched marking at the other end.

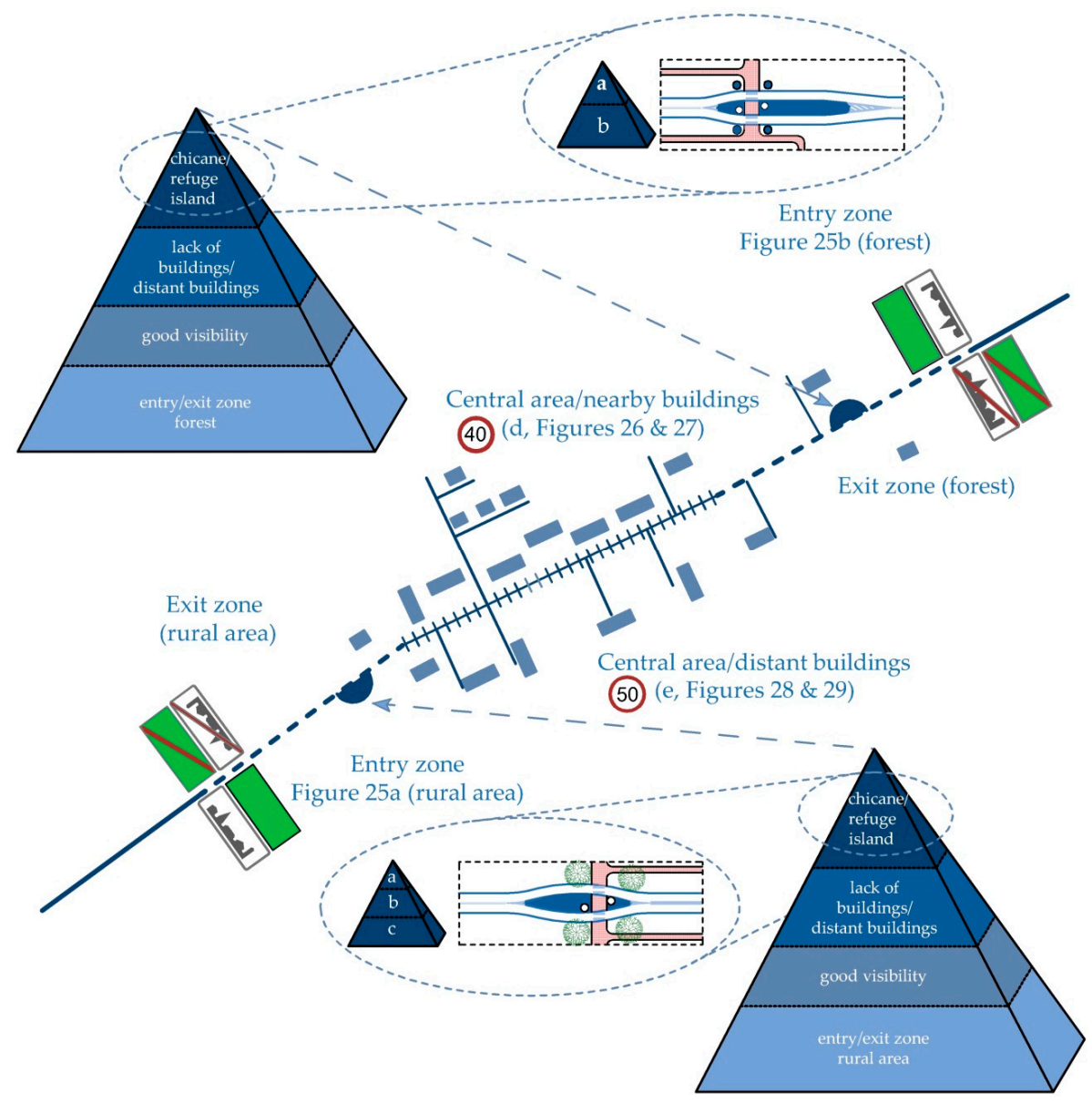

Figure 24. Flow chart for designing pedestrian refuges on sections of regional roads in villages. ${ }^{a}$ interactive road signs; ${ }^{b}$ barrier bollards; ${ }^{c}$ additional plantings; ${ }^{d}$ pedestrian refuges with post-and-chain barriers or barrier bollards (Figures 26 and 27); e pedestrian refuges combined with kerb buildouts (bulb-outs) or pinchpoints (Figures 28 and 29).

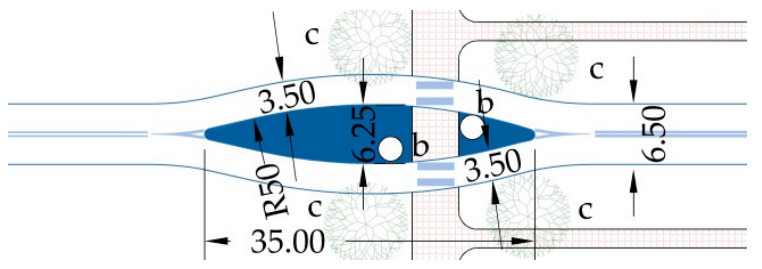

(a)

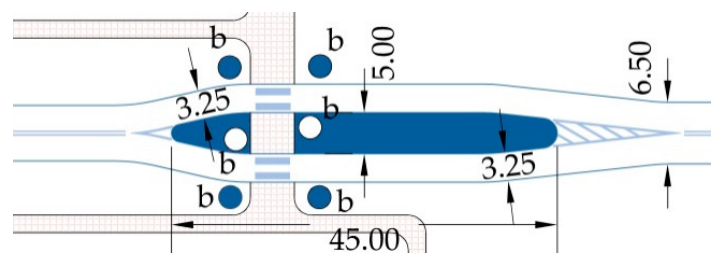

(b)

Figure 25. Procedure for designing pedestrian asylums in entry zone: (a) rural area; (b) forest. ${ }^{b}$ barrier bollards U-12c; ${ }^{\mathrm{c}}$ additional plantings. 


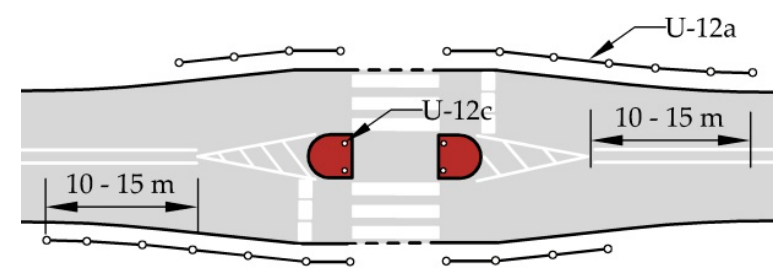

(a)

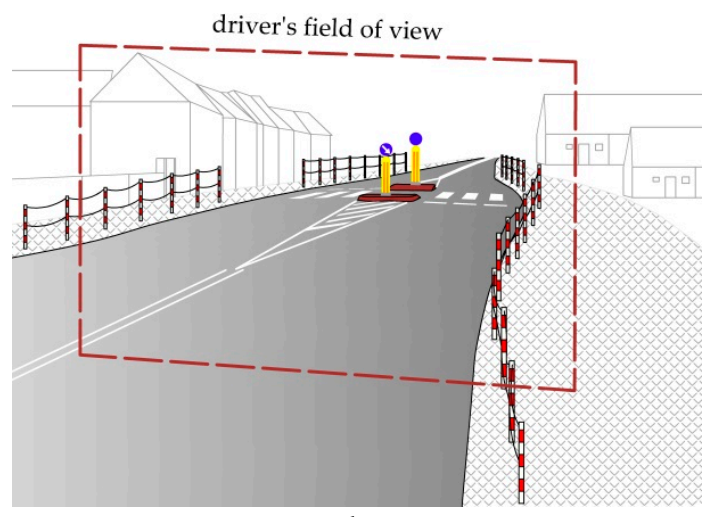

(b)

Figure 26. Schematic design of pedestrian refuge enhanced by post-and-chain barriers U12-a: (a) plan view; (b) visualisation of the proposed design (drawings by Agata Misztal).

Figures 26 and 27 present recommendations for village centre area with residential buildings in close proximity, where the pedestrian refuges are enhanced by post-and-chain barriers or barrier bollards to achieve yet smaller speeds and improve the safety of pedestrians right on the crossing.

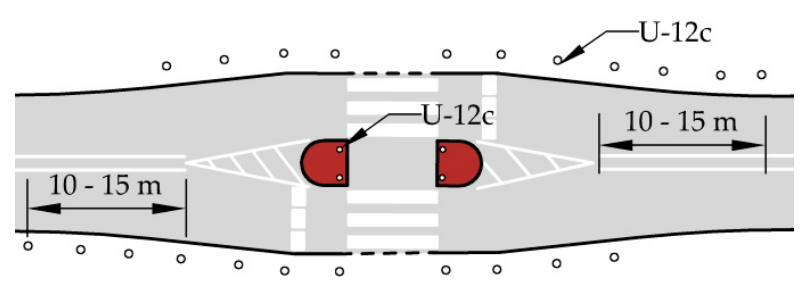

(a)

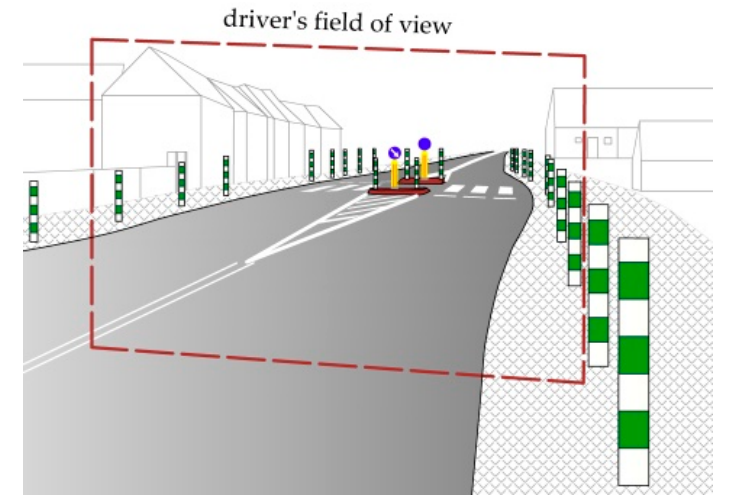

(b)

Figure 27. Schematic design of pedestrian refuge enhanced by barrier bollards U12-c: (a) plan view; (b) visualisation of the proposed design (drawings by Agata Misztal).

Based on the results of this research, the authors recommend symmetric pedestrian refuge islands, $2 \mathrm{~m}$ or $2.5 \mathrm{~m}$ wide, the latter to accommodate bicycles, if required, as an appropriate design for the village centre areas. In order to highlight the pedestrian refuge location and influence the driver's perception, it should be accompanied with post-and-chain barriers [5,7] or barrier bollards of various colours and sizes, the latter being a popular measure used in the West European countries. Examples of designs used in Poland are presented in Figures 18 and 23. Figure 26, in turn, shows the proposed design including post-and-chain barriers. According to [5] the post-and-chain barriers should extend ca. 10-15 $\mathrm{m}$ upstream of the pedestrian refuge, measuring from the end of the hatched marking and at least to the end of the hatched marking at the other end.

The travel lane width should be appropriate to the level of service of the road in question. Over the pedestrian crossing length, the travel lane design should not depart from the design on the straight section, the width to comply with the guidelines of $[5,6]$. According to the recommendations of [5] the width of the travel lane right before and after the pedestrian refuge should be in compliance with the adopted vehicle turning path templates. The angles of hatched marking border lines should follow the recommendations of [6] and the widths of lanes alongside the tapers should provide enough room for the vehicles to pass. 
As mentioned earlier, in the West European countries' barrier bollards are used increasingly often at the pedestrian refuges and at the accompanying kerb buildouts. Barrier bollards can be installed both before and after the pedestrian refuge, as shown in Figure 27. They can be installed quicker and at a lower cost than the post-and-chain barriers. Another advantage of barrier bollards is that, in accordance with the guidelines of [7] they can have a decorative form, matching the surroundings and can be finished in colour chosen by the landscape architect. In the West European countries, barrier bollards are fitted with fluorescent strips or LED lighting at the top. The purpose of these treatments is to enhance perception of bollards in limited lighting conditions, during rainfall, at dusk or during the night.

A review of the designs used in West European countries, recommended in the design manuals [16,17] showed that kerb buildouts (bulb-outs) placed symmetrically on either side of the road or pinchpoints are often provided at the pedestrian refuges or gateway islands, as shown in Figures 28 and 29.

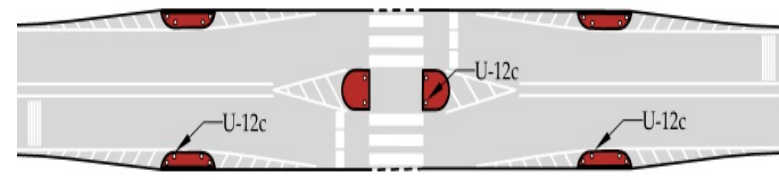

(a)

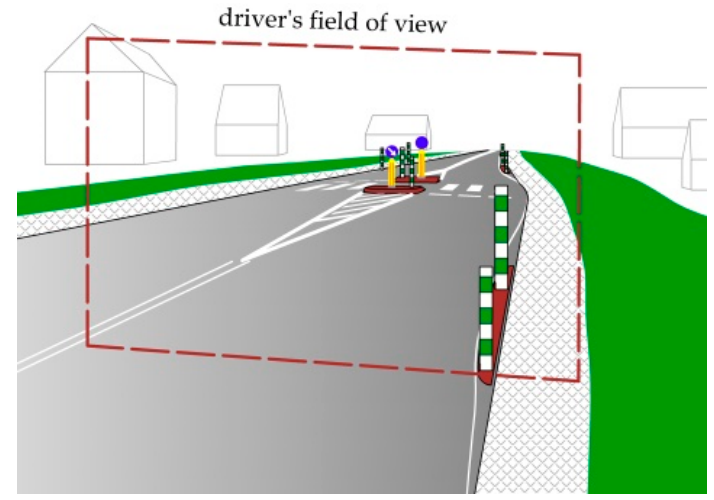

(b)

Figure 28. Schematic design of pedestrian refuge enhanced by bulb-outs: (a) plan view; (b) visualisation of the proposed design (drawings by Agata Misztal).

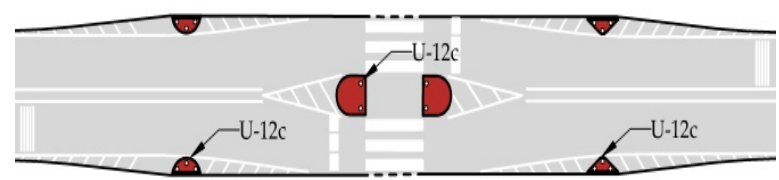

(a)

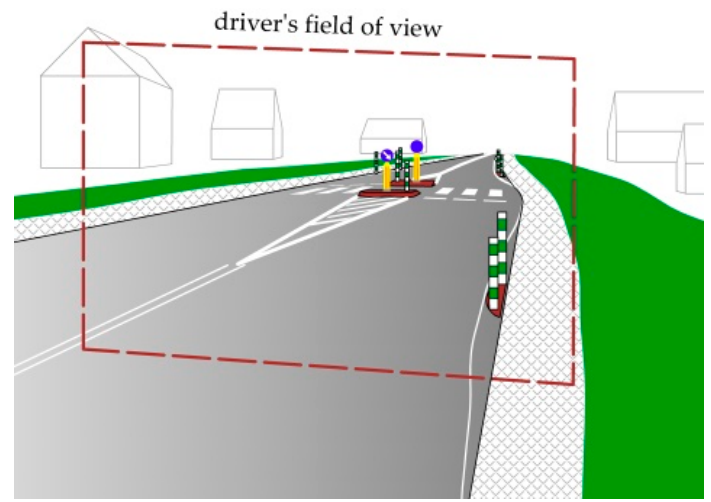

(b)

Figure 29. Schematic design of pedestrian refuge enhanced by a pinchpoint: (a) plan view; (b) visualisation of the proposed design (drawings by Agata Misztal).

The side islands can incorporate, as in the West European countries, greenery and four barrier bollards in corners. However, the most important design feature is raised kerbing around the island, provided in order to enhance lateral shift of vehicles and in this way contribute to reducing the speeds to the desired level. Moreover, the side islands should include U-6b object marker signs and signs communicating the horizontal deflection.

The U.S. [16] and U.K. [17] guidelines recommend also using of pinchpoints which are smaller kind of side islands (Figure 29). Due to a smaller size, these islands require a shorter section of widened 
carriageway and, for this reason, are an option of choice for village centre areas. In this case, they should also be provided with raised kerbing around the perimeter. In the West European countries, planters are placed on them to fit the village centre streetscape. Usually they are enhanced by three barrier bollards placed at the island corners. Although in most cases the islands are triangular in shape, semi-circular islands can also be found. In any case, the islands must incorporate U-6b object markers and bollards. Sometimes, depending on the traffic control scheme, C-10 keep left signs are placed atop the U-6b object markers.

\section{Conclusions}

The results of this research allow us to conclude that pedestrian refuges imposing symmetric lateral shift by $1 \mathrm{~m}$ which are not accompanied by street furniture items have no significant bearing on speed reduction in their vicinity, and this irrespective of their sitting along the stretch of road in the village and geometry of associated pavement markings. Conversely, asymmetric lateral shift in the travelway alignment generated by the refuge island located on one side of the road centreline induces a considerable speed reduction, yet only when the driver sees residential buildings in close proximity of the road.

If a pedestrian refuge located in the village centre area with residential buildings in close proximity of the road is expected to bring down the $v_{85}$ speed to $40 \mathrm{~km} / \mathrm{h}$, it must be symmetrical, induce $1 \mathrm{~m}$ lateral shift and be enhanced by post-and-chain barriers or barrier bollards. When the desired maximum speed in the village area is $50 \mathrm{~km} / \mathrm{h}$ and the nearest residential buildings are situated away from the road, the islands should be symmetrical, induce $1 \mathrm{~m}$ lateral shift and be accompanied by bulb-outs or pinchpoints.

In the village entry zones in open rural areas with scattered residential buildings situated away from the road, pedestrian refuges should be combined with lens-shaped symmetric gateway islands, $6.25 \mathrm{~m}$ wide at the widest point. They should be enhanced by planting trees and placing crash-resistant bollards along the footway to influence the drivers' perception and make them alert for pedestrians. On sections surrounded by a forest, cigar-shaped symmetric central islands should be used to save trees by reducing the land take in comparison to lens-shaped islands. These islands must be at least $5 \mathrm{~m}$ wide in any case. On sections surround by a forest the pedestrian crossings should be enhanced with barrier bollards. In both cases interactive road signs should be used, coupled with motion sensors, to enhance perception of pedestrians in adverse weather.

Author Contributions: conceptualization, A.S.; methodology, A.S.; formal analysis, A.S. and D.K.; investigation, A.S. and D.K.; resources, A.S. and D.K.; data curation, A.S.; writing-original draft preparation, A.S.; writing-review and editing, A.S. and D.K.; visualization, A.S. and D.K.; supervision, A.S.; project administration, A.S.; funding acquisition, D.K.

Funding: The researches included in the paper were partly financed by grants of WBiA ZUT: DKD Decision No. 517-02-033-6728/17.

Conflicts of Interest: The authors declare no conflict of interest.

\section{Appendix A}

\begin{tabular}{|c|c|c|l|}
\hline No. & Sign & Symbol & Description \\
\hline 1 & & P-7b & $\begin{array}{l}\text { Pavement marking between the travel lane and } \\
\text { shoulder (continuous edgeline) }\end{array}$ \\
& P & & \\
& P-7b & & \\
\hline
\end{tabular}




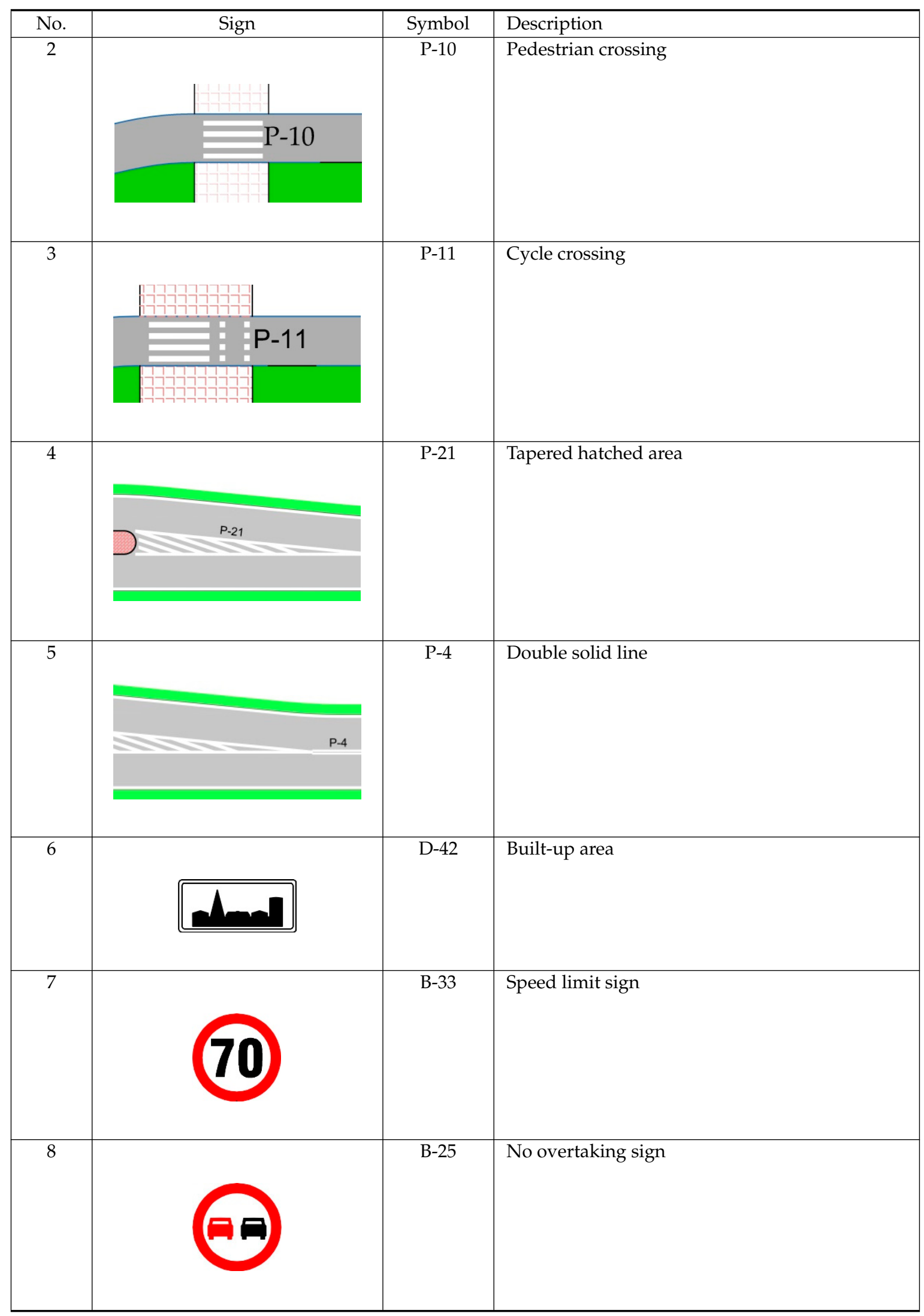




\begin{tabular}{|c|c|c|l|}
\hline No. & Sign & Symbol & Description \\
\hline 9 & & U-12a & Post-and-chain barrier \\
\hline 10 & & U-12c & Barrier bollard(s) \\
\hline 11 & & U-6b & Object marker sign \\
\hline 12 & & & \\
\hline & & & \\
\hline & & & \\
\hline & & & \\
\hline
\end{tabular}

\section{References}

1. Krystek, R.; Jamroz, K.; Michalski, L.; Banach, B.; Budzyński, M.; Kastner, M.; Kustra, W.; Ryś, A.; Oskarbska, I.; Romanowska, M. Traffic Calming Engineering on the Roads of the Pomorskie Region in Poland, Part 1: Urban Street Layouts; GAMBIT Pomorski: Gdańsk, Poland, 2008.

2. Jamroz, K. (Ed.) Methodology of Systemic Behavioral Studies and Relationships with Drivers; National Road Safety Council of Poland: Warszawa, Poland; Gdańsk, Poland, 2015.

3. Gaca, S.; Kieć, M. Assessment of Pedestrian Safety Hazards on Designated Pedestrian Crossings in Relation to Vehicle Speeds. Logistyka 2014, 3, 1844-1853.

4. Vignali, V.; Cuppi, F.; Acerra, E.; Bichicchi, A.; Lantieri, C.; Simone, A.; Costa, M. Effects of Median Refuge Island and Flashing Vertical Sign on Conspicuity and Safety of Unsignalized Crosswalks. Transp. Res. Part F 2018, 60, 427-439. [CrossRef]

5. Jamroz, K. (Ed.) Protection of Pedestrians. Manual for Pedestrian Traffic Management Bodies; National Road Safety Council of Poland: Gdańsk, Kraków; Warszawa, Poland, 2014.

6. Ordinance of the Minister of Transport and Maritime Economy of 2 March 1999. Published in the Polish Journal of Laws, Issue No. 43, Item No. 430, as Subsequently Amended; Warszawa, Poland, 1999.

7. Schedules No. 1-4 to the Ordinance of the Minister of Infrastructure of 3 July 2003 on the Engineering Requirements for Road Signs and Signals and Traffic Safety Devices and Placement Considerations. Published in the Polish Journal of Laws, Warszawa, Poland, 2003. 
8. Safe Road Design Manual Amendments to the WB Manual, Consulting Services for Safe Road Design; SweRoad: Stockholm, Sweden, 2011.

9. Pedestrian Compatible Planning and Design Guidelines; State of NJ DOT: New York, NY, USA, 1998.

10. Islam, K.T.; Raj, R.G.; Mujtaba, G. Recognition of Traffic Sign Based on Bag-of-Words and Artificial Neural Network. Symmetry 2017, 9, 138. [CrossRef]

11. Sawada, T.; Li, Y.; Pizlo, Z. Any Pair of 2D Curves Is Consistent with a 3D Symmetric Interpretation. Symmetry 2011, 3, 365-388. [CrossRef]

12. Jayadevan, V.; Sawada, T.; Delp, E.; Pizlo, Z. Perception of 3D Symmetrical and Nearly Symmetrical Shapes. Symmetry 2018, 10, 344. [CrossRef]

13. Directives for the Design of Urban Roads; RASt 06; Road and Transportation Research Association: Köln, Germany, 2012.

14. Wirksamkeit Geschwindigkeitsdämpfender Maßnahmen Außerorts; Hessisches Landesamt für Straßen- und Verkehrswesen: Hessen, Germany, 1997.

15. Kacprzak, D.; Sołowczuk, A. Synergy effect of speed management and development of road vicinity in Wrzosowo. In Proceedings of the Conference Web of Science, World Multidiscipinary Civil Engineering-Architecture-Urban Planning Symposium, Prague, Czech Republic, 18-22 June 2018.

16. Guidelines for Traffic Calming; City of Sparks Public Works Traffic Division: Reno, NV, USA, 2007.

17. Traffic Calming, Local Transport, Note 1, Department for Transport, Department for Regional Development (Northern Ireland), Scottish Executives, Welsh Assembly Government; TSO: Dublin, UK, 2007.

(C) 2019 by the authors. Licensee MDPI, Basel, Switzerland. This article is an open access article distributed under the terms and conditions of the Creative Commons Attribution (CC BY) license (http://creativecommons.org/licenses/by/4.0/). 